\title{
High accuracy measurements of dry mole fractions of carbon dioxide and methane in humid air
}

\author{
C. W. Rella ${ }^{1}$, H. Chen ${ }^{2}$, A. E. Andrews ${ }^{2}$, A. Filges ${ }^{3}$, C. Gerbig ${ }^{3}$, J. Hatakka ${ }^{4}$, A. Karion ${ }^{2,7}$, N. L. Miles ${ }^{5}$, \\ S. J. Richardson ${ }^{5}$, M. Steinbacher ${ }^{6}$, C. Sweeney ${ }^{2,7}$, B. Wastine ${ }^{8}$, and C. Zellweger ${ }^{6}$ \\ ${ }^{1}$ Picarro, Inc., Santa Clara, CA, USA \\ ${ }^{2}$ National Oceanic and Atmospheric Administration, Earth System Research Laboratory, \\ Global Monitoring Division, Boulder, CO, USA \\ ${ }^{3}$ Max Planck Institute for Biogeochemistry, Jena, Germany \\ ${ }^{4}$ FMI, Finnish Meteorological Institute, Helsinki, Finland \\ ${ }^{5}$ The Pennsylvania State University, Department of Meteorology, University Park, PA, USA \\ ${ }^{6}$ Empa, Swiss Federal Laboratories for Materials Testing and Research, \\ Laboratory for Air Pollution/Environmental Technology, Duebendorf, Switzerland \\ ${ }^{7}$ CIRES, University of Colorado, Boulder, CO, USA \\ ${ }^{8}$ Laboratoire des Sciences du Climat et l'Environnement, Gif sur-Yvette, France
}

Correspondence to: C. W. Rella (rella@picarro.com)

Received: 31 July 2012 - Published in Atmos. Meas. Tech. Discuss.: 21 August 2012

Revised: 27 February 2013 - Accepted: 27 February 2013 - Published: 27 March 2013

\begin{abstract}
Traditional techniques for measuring the mole fractions of greenhouse gases in the well-mixed atmosphere have required dry sample gas streams (dew point $<-25^{\circ} \mathrm{C}$ ) to achieve the inter-laboratory compatibility goals set forth by the Global Atmosphere Watch programme of the World Meteorological Organisation (WMO/GAW) for carbon dioxide $( \pm 0.1 \mathrm{ppm}$ in the Northern Hemisphere and $\pm 0.05 \mathrm{ppm}$ in the Southern Hemisphere) and methane ( $\pm 2 \mathrm{ppb})$. Drying the sample gas to low levels of water vapour can be expensive, time-consuming, and/or problematic, especially at remote sites where access is difficult. Recent advances in optical measurement techniques, in particular cavity ring down spectroscopy, have led to the development of greenhouse gas analysers capable of simultaneous measurements of carbon dioxide, methane and water vapour. Unlike many older technologies, which can suffer from significant uncorrected interference from water vapour, these instruments permit accurate and precise greenhouse gas measurements that can meet the WMO/GAW inter-laboratory compatibility goals (WMO, 2011a) without drying the sample gas. In this paper, we present laboratory methodology for empirically deriving the water vapour correction factors, and we summarise a series of in-situ validation experiments comparing the measure-
\end{abstract}

ments in humid gas streams to well-characterised dry-gas measurements. By using the manufacturer-supplied correction factors, the dry-mole fraction measurements have been demonstrated to be well within the GAW compatibility goals up to a water vapour concentration of at least $1 \%$. By determining the correction factors for individual instruments once at the start of life, this water vapour concentration range can be extended to at least $2 \%$ over the life of the instrument, and if the correction factors are determined periodically over time, the evidence suggests that this range can be extended up to and even above $4 \%$ water vapour concentrations.

\section{Introduction}

In recent decades, there has been growing scientific consensus that the increase in the concentrations (i.e., dry mole fractions) of several key long-lived species in the atmosphere is contributing to an overall global warming trend via the radiative forcing effect (IPCC, 2007). Carbon dioxide is the largest contributor to the total increase in radiative forcing (since pre-industrial times), accounting for $62.9 \%$ of the total radiative forcing by all long-lived greenhouse gases in

Published by Copernicus Publications on behalf of the European Geosciences Union. 
2005 (IPCC, 2007); methane is the second largest single contributor at $18.2 \%$ of the 2005 total (IPCC, 2007). Together, these two greenhouse gases accounted for $81 \%$ of the total radiative forcing globally. Between 1990 and 2010, carbon dioxide accounted for $79.5 \%$ of the increase in radiative forcing (WMO, 2011b), with methane contributing an additional $5.0 \%$ of the increase. Because these gases are longlived in the atmosphere (IPCC, 2007), the effects of emissions on the energy balance of the atmosphere are cumulative over their atmospheric lifetimes. Since 1958, with the installation of the first continuous greenhouse gas observing station on Mauna Loa, Hawaii (Keeling, 1960), scientific focus on quantifying carbon dioxide and methane mole fractions in the well-mixed atmosphere has increased significantly, with the goal of using these data for quantifying the magnitude and rate of the sources and sinks of these gases. Today, there are extensive networks of such background or regional monitoring stations, with many more being brought online with each passing year. These measurement networks provide crucial validation of anthropogenic emissions as well as constraining the role of the biosphere and the oceans in modulating the concentrations observed in the atmosphere. The increasing spatial resolution afforded by these networks is already leading to higher resolution emission quantification, from global/continental scales (Bousquet et al., 2000; Enting et al., 1995; Fan, 1998; Gurney et al., 2002; Peters et al., 2007, 2010; Peylin et al., 2005; Schuh et al., 2010) to regional scales (Corbin et al., 2010; Lauvaux et al., 2009, 2012a, b; Matross et al., 2006; Tolk et al., 2009) to even municipal scales (McKain et al., 2012).

The rapid expansion of greenhouse gas monitoring networks has driven the need for simpler and easier methods for making greenhouse gas measurements. Traditional methods of measuring the mole fractions of greenhouse gas in the well-mixed atmosphere have relied upon non-dispersive infrared (NDIR) spectroscopy for carbon dioxide and Gas Chromatography (GC) for methane. Typically, these measurements are performed on dry samples because the mole fractions for carbon dioxide and methane are only meaningful for understanding global greenhouse gas budgets when extrapolated back to dry-gas conditions. When water vapour is added to or removed from a sample of ambient air, via evaporation or condensation processes, the mole fraction of all the other gases (including carbon dioxide and methane) in the sample are also affected via dilution by water vapour. As a volatile component of the atmosphere, water vapour can vary rapidly geographically and in time, and this variability will mask, via the dilution effect, the less variable concentration of $\mathrm{CO}_{2}$ and $\mathrm{CH}_{4}$. Generally, it has not been possible to achieve the overall inter-laboratory compatibility goal stipulated by the WMO/GAW programme for $\mathrm{CO}_{2}( \pm 0.1 \mathrm{ppm})$ and $\mathrm{CH}_{4}$ ( $\pm 2 \mathrm{ppb}$ ) (WMO, 2011a) with these technologies without eliminating or rigorously accounting for humidity differences between sample and standard air. A water vapour mole-fraction of $500 \mathrm{ppm}$ (dew point $-32^{\circ} \mathrm{C}$ at 1 bar) causes a dilution bias of $0.2 \mathrm{ppm}$ toward lower $\mathrm{CO}_{2}$ readings. Thus, in order to compute accurate mole fractions relative to dry standards, it is necessary to dry samples to very low levels of water vapour. The dilution effect is proportional to the humidity difference between standards and samples, rather than the absolute water amount, and the approach employed by Bakwin et al. (1995) is to dry the sample gas to a more moderate level $\left(-25^{\circ} \mathrm{C}\right.$ dew point) and humidify the standard gases to the same extent by passing both the sample and standard gases through a common Nafion membrane dryer.

Given the fact that dry-gas measurements are the ultimate goal, it would seem to be appropriate to dry the samples prior to measurement. However, installing drying systems brings several disadvantages:

1. drying systems add both cost and complexity to the sampling system, increasing the number of fittings and, thus, the chances of leaks;

2. these systems often require consumables that require periodic replacement;

3. the drying systems often rely on hardware that can fail (e.g., heated rechargeable desiccators) or on materials whose performance can degrade over time (e.g., Nafion membranes);

4. many drying systems require at least some human intervention periodically to ensure proper operation, which is a significant drawback at remote sites where access is limited;

5. they often increase the wetted surface area of the inlet system, increasing the residence time;

6. methods for drying may also induce biases in the dry mole fraction, by affecting (positively or negatively) the mole fraction of the analyte gas in the sample stream during the process of drying. For example, the permeability of Nafion to carbon dioxide has been shown to depend strongly upon the amount of humidity in the gas stream (Ma and Skou, 2007);

7. some drying methods are also sensitive to changes in ambient temperature or pressure;

8. dryers can be impractical to implement robustly on aircraft, which provide critical vertical profiles of greenhouse gases in the troposphere;

9. finally, and perhaps most importantly, dryers prevent measurements of ambient water vapour, unless a dedicated water vapour sensor is installed upstream of the dryer. Water vapour provides a critical tracer for identifying atmospheric layers such as the boundary layer top from airborne measurements, or changes in air masses on stationary towers (Gupta et al., 2009), and can additionally provide a valuable indicator of water condensation or ingress into the inlet sampling manifold. 
Clearly, it would be a significant practical advantage to be able to measure dry-gas mole fractions for carbon dioxide and methane directly in the humid gas sample, which would in turn simplify the rapid, reliable and cost-effective deployment of large measurement networks. However, it has hitherto been impractical to make measurements in humid gas, not only because many traditional techniques suffer from significant cross-interference between water vapour, carbon dioxide and methane (cross-interference is where variations in the mole fraction of one gas affects the reported reading of the other gases), but also because until recently, water vapour measurements of sufficient stability and precision have not been practical in the field. With an analyser that can directly measure the water vapour content of the air at the same time as carbon dioxide and methane, the dry gas mole fractions of these two critically important greenhouse gases can be directly quantified with high precision and high accuracy, even in very humid conditions such as in tropical regions.

In recent years, advances in optical spectroscopy have led to the development of a new class of greenhouse gas analysers capable of simultaneous measurements of carbon dioxide, methane and water vapour. These instruments have been shown to require infrequent calibration (less than once per day) to meet WMO/GAW (inter-laboratory compatibility) goals (Richardson et al., 2012; Andrews et al., 2013). In this paper, we will focus on analysers based upon cavity ring down spectroscopy (CRDS) manufactured by Picarro, Inc. (Santa Clara, CA). In particular, we consider those instruments which measure $\mathrm{CO}_{2}, \mathrm{CH}_{4}$, and $\mathrm{H}_{2} \mathrm{O}$ : the $\mathrm{G} 1301$, G2301, and G2401 models (note: the G2302 model uses a different spectroscopic feature to measure water vapour, and for simplicity and consistency will not be considered here). The G1301 model was the first commercial instrument of this type (Crosson, 2008). The G2301 model measures the same species as the G1301 model, and the G2401 model measures carbon monoxide as well as the other three constituents. These later instruments are based on the same core optical spectrometer as the G1301 with essentially identical performance characteristics. For the purpose of this paper, they will be assumed to behave identically in regard to the dry-mole fraction correction of $\mathrm{CO}_{2}$ and $\mathrm{CH}_{4}$ (to date, no operationally significant differences have been noted). We note that any measurement system that is capable of measurements of carbon dioxide, methane and water vapour, without substantial systematic bias and interspecies cross-interference, can in principle deliver GAWquality greenhouse gas measurements in humid gas streams.

These analysers are all based upon CRDS, an optical technology in which direct measurement of infrared absorption loss in a sample cell is used to quantify the mole-fraction of the gas. Laser light is directed into an optical resonator (called the optical cavity) consisting of three highly reflective mirrors, which serves as a compact flow cell with a volume of less than 10 standard $\mathrm{cm}^{3}$ and an effective optical path length of $15-20 \mathrm{~km}$. This long path length allows for measurements with high precision (with ppb or even partsper-trillion uncertainty, depending on the analyte gas), using compact and highly reliable near-infrared laser sources. The instrument employs precise monitoring and control of the optical wavelength which delivers sub-picometer wavelength targeting on a microsecond timescale. The resulting spectrograms are analysed using nonlinear spectral pattern recognition routines, and the outputs of these routines are converted into gas concentrations with a typical precision of about $0.05 \mathrm{ppm}$ for $\mathrm{CO}_{2}$ and $0.3 \mathrm{ppb}$ for $\mathrm{CH}_{4}$ in a $5 \mathrm{~s}$ measurement. The gas temperature and pressure are tightly controlled in these instruments (Crosson, 2008). This stability allows the instrument (when properly calibrated to traceable reference standards) to deliver accurate measurements that need very infrequent calibration relative to other $\mathrm{CO}_{2}$ and $\mathrm{CH}_{4}$ instrumentation.

In these instruments, separate and distinct spectral lines are used for each measured species. The lines have been carefully selected to provide high precision, and little or no interference from other nearby spectral lines of other atmospheric constituents. At a given temperature and pressure (which are stabilised to within $10 \mathrm{mK}$ and 0.05 Torr of the internal set points, respectively), and in a given gas composition, the characteristics of these spectral lines do not vary; the line strength and line shape are intrinsic properties of the target molecule. That fact combined with the Beer-Lambert law, which dictates that the absorption per unit length at the peak of a spectral line is proportional to the number of molecules in the gas sample, means that the response of the instrument is linear to increases in mole fraction.

A critical requirement for stable instrument performance is that the background (i.e., non-analyte) gas composition does not change. The background gas composition has a significant effect upon the line shape. Different gases have different broadening cross-sections and, therefore, broaden the spectral line to varying degrees; for example, $1 \mathrm{ppm}$ of carbon dioxide in nitrogen has a broader line with lower peak height than $1 \mathrm{ppm}$ of carbon dioxide in oxygen. For most variations in ambient air, these effects are negligible, because the mole fractions of most components of the background gas matrix do not vary by a large amount in regular air samples. For example, the oxygen to nitrogen ratio varies less than 500 per meg (parts per million of the ratio) in urban air (Keeling, 1988), and less than 250 per meg at remote locations (Keeling et al., 1992). Of more significant concern are variations in the $\mathrm{O}_{2} / \mathrm{N}_{2}$ ratio present in calibration and target tanks. Specifically, in standards generated from synthetic air, the fraction of $\mathrm{O}_{2}$ can vary from 18 to $24 \%$, depending on the manufacturer. Furthermore, Ar, which is present in whole air at a level of $0.9 \%$, is often absent from synthetic air. In addition, there are certainly other applications where the $\mathrm{O}_{2} / \mathrm{N}_{2}$ ratio can be far from the standard clean air values, such as when equilibrating $\mathrm{CO}_{2}$ or $\mathrm{CH}_{4}$ in seawater where $\mathrm{O}_{2}$ mole fraction can vary by $20 \%$, resulting in significant changes in the $\mathrm{CO}_{2}$ and $\mathrm{CH}_{4}$ peak heights. In Nara et 
al. (2012), the effects of $\mathrm{O}_{2}, \mathrm{~N}_{2}$, and Ar on the spectral lines used in the Picarro instrumentation have been carefully characterised and quantified. Provided the concentrations of these gases are known, it is possible to correct for their effects. No correction is necessary provided that standards generated from ambient air are used.

Similarly, the range of water vapour content can be extremely large in the troposphere, ranging from 100$500 \mathrm{ppm}$ in arctic regions or dry alpine deserts to more than $40000 \mathrm{ppm}(4 \%)$ in rainforests and other warm and humid environments. The variations of water vapour in the atmosphere modify the mole fractions of $\mathrm{CO}_{2}$ and $\mathrm{CH}_{4}$ via the dilution effect. In addition, the analyte line will experience a variable amount of broadening due to variability of water vapour in the background gas matrix. The water correction methodology described below accounts for both of these biases.

This paper is organised as follows. We begin with a short discussion of the theory behind the effects of water vapour on the measurement of dry mole fractions of carbon dioxide and methane. Next, we present several alternative experimental methods for determining the empirical correction factors necessary to calculate dry mole fractions from measurements of the humid gas mole fractions of $\mathrm{CO}_{2}, \mathrm{CH}_{4}$ and $\mathrm{H}_{2} \mathrm{O}$. The results of instrument-to-instrument variations in the correction factors, and the drift in the correction factors over time on a single instrument, are also presented, along with an uncertainty analysis. Next, we present the results of several insitu side-by-side comparisons of measurements in humid gas to well-validated dry-gas measurement systems. Finally, we conclude with a summary.

\section{Effects of water vapour on the measurements of car- bon dioxide and methane}

For greenhouse gas measurements and inversion analysis, dry-gas mole fractions (moles analyte gas/moles air) for carbon dioxide and methane are the relevant physical quantities to report; variability in these mole fractions, due to fluctuations in water vapour due to evaporation and condensation processes, only masks the underlying atmospheric variations resulting from surface-atmosphere exchange fluxes. The diluted- and dry-gas mole fractions are related by the following expression:

$$
\frac{c_{\text {dilution }}}{c_{\text {dry }}}=1-0.01 H_{\text {act }}
$$

where $c$ is the mole fraction of carbon dioxide or methane (the same equation holds for each), and $H_{\text {act }}$ is the actual water mole fraction (in \%). The challenge of implementing even this simple equation becomes immediately apparent: the water mole fraction $H_{\text {act }}$ must be known to a high degree of both precision and accuracy, to support a high degree of accuracy in the measured dry gas concentrations. For example, to maintain an uncertainty of less than $50 \mathrm{ppb}$ on a $400 \mathrm{ppm}$ carbon dioxide measurement, the water vapour measurement must be accurate and precise to within $0.0125 \%$, or $125 \mathrm{ppm}$. This requirement exceeds the limit of the reference method for hygrometry, the chilled mirror method, which typically guarantees an accuracy of $0.1^{\circ} \mathrm{C}$ dew point, which is $34 \mathrm{ppm}$ at $10^{\circ} \mathrm{C}$ but $260 \mathrm{ppm}$ at $30^{\circ} \mathrm{C}$.

Rather than use Eq. (1) directly, which requires an accurate determination of $H_{\text {act }}$ (and $c_{\text {dilution }}$ ), we instead derive empirical forms that relate the highly precise but humiditybiased outputs $\left(\mathrm{CO}_{2}\right)_{\text {wet }},\left(\mathrm{CH}_{4}\right)_{\text {wet }}$, and $\left(\mathrm{H}_{2} \mathrm{O}\right)_{\text {rep }}$ to dry mole fractions of $\mathrm{CO}_{2}$ and $\mathrm{CH}_{4}$. Then, by performing the appropriate experiments (described in Sect. 3), dry-mole fractions may then be provided without ever needing to determine the absolute calibration of the water vapour. This empirical relationship is derived below.

The quantity $c_{\text {dilution }}$ exhibits systematic bias due to water vapour via changes in the spectroscopic line shape. There are three principal mechanisms that determine the spectral line shape for isolated ro-vibrational lines, such as those used in the CRDS instrumentation discussed here: Doppler broadening, Lorentzian broadening, and Dicke line narrowing (Varghese and Hanson, 1984). The Doppler broadening coefficient is an intrinsic property of the analyte molecule, and does not depend on the constituents of the background gas composition. However, the Lorentzian broadening and Dicke line narrowing effects do depend both on the analyte gas and on the constituents of the background gas composition. Thus, as the concentration of water vapour changes, the shape of the spectral line changes. In spectroscopy, the total area of the spectral line is conserved throughout this process. However, the Picarro instrumentation uses peak height rather than area as a quantitative measure of the concentration, due to the fact that the measurement of peak height is more precise and more stable than the area measurement. As a result, the peak height of the absorption features for carbon dioxide and methane have a systematic bias with increasing water vapour due to the effect of the water vapour on both the line broadening and line narrowing effects. A more detailed treatment of these line shape effects is given in Nara et al. (2012) for the broadening effects of oxygen, nitrogen and argon; a completely analogous treatment applies to water vapour.

As a result, we find that the effect of water vapour on the analyte peak heights can be expressed by a Taylor series expansion in water vapour concentration (measured as a mole fraction in \%), and the effect is also proportional to the analyte gas peak height. Thus, the lineshape effect on the peak height of carbon dioxide or methane due to water vapour is proportional to the peak height itself, but it can be nonlinear in water vapour concentration due to higher order terms in the Taylor series. We model this effect with the following expression:

$$
\frac{c_{\mathrm{wet}}}{c_{\text {dilution }}}=1+x H_{\mathrm{act}}+y H_{\mathrm{act}}^{2}
$$


Here, we have kept terms to second order in the water vapour concentration. $x$ and $y$ are the first two terms of Taylor expansion, equal to the partial derivative of the ratio on the left-hand side with respect to the water concentration.

The final step is to relate the actual water vapour concentration $H_{\text {act }}$ to the measured water vapour concentration $H_{\text {rep }}$, which is again derived from the peak height of a water vapour line. This line suffers from a similar lineshape effect that affects the carbon dioxide and methane lines with increasing water vapour concentration (called self-broadening), which leads to a nonlinearity in the measured water scale. This nonlinearity is expressed in the following way (again, keeping terms to second order):

$H_{\text {act }}=r_{1} H_{\text {rep }}+r_{2} H_{\text {rep }}^{2}$

The values $r_{1}$ and $r_{2}$ in ambient air were determined by Winderlich et al. (2010) to be 0.772 and 0.019493 , respectively, comparing against a calibrated hygrometer, with a relative accuracy of $\pm 1.5 \%$. We emphasise that any uncertainty in these values does not affect the determination of the correction coefficients (as is shown below). Equation (1)-(3) can then be combined, resulting in the following expression (after grouping terms and keeping all terms 2 nd order and lower):

$\frac{c_{\mathrm{wet}}}{c_{\mathrm{dry}}}=1+a H_{\mathrm{rep}}+b H_{\mathrm{rep}}^{2}$

Note that $c_{\text {wet }}, c_{\text {dry }}$, and $H_{\text {rep }}$ are all values that can be determined directly from a properly designed experiment (which are discussed below), which means that the constants $a$ and $b$ (which are different for $\mathrm{CO}_{2}$ and $\mathrm{CH}_{4}$ ) can be determined entirely empirically, without ever measuring the intermediate constants $x, y, r_{1}$, and $r_{2}$. In other words, no specific knowledge of the lineshape effects on any of the species is required to derive this empirical relationship. In addition, note that high accuracy water vapour measurements are not required for the correction proposed in this paper; what is required is a high degree of precision and stability. As long as $H_{\text {rep }}$ is a well-behaved, monotonically increasing function of the actual water vapour concentration, $H_{\text {rep }}$ is a functionally identical equivalent measure of water vapour for the purposes of correcting the $\mathrm{CO}_{2}$ and $\mathrm{CH}_{4}$ measurements. When discussing the laboratory experiments, we will use $H_{\text {rep }}$, because this quantity is more physically relevant for the correction, because it is derived directly from the absorbance peak as measured by the optical spectrometer. However, when presenting ambient air measurements, we will use $H_{\text {act }}$, because this quantity is more physically relevant in the atmosphere.

The correction coefficients determined by Chen et al. (2010) are as follows:

$$
\begin{aligned}
& \mathrm{CO}_{2}: a=-1.20 \times 10^{-2}, b=-2.67 \times 10^{-4} \\
& \mathrm{CH}_{4}: a=-9.823 \times 10^{-3}, b=-2.39 \times 10^{-4}
\end{aligned}
$$

Obviously, the precision of the dry-mole fractions of $\mathrm{CO}_{2}$ and $\mathrm{CH}_{4}$ is degraded somewhat by the finite precision of the water vapour measurement as modified by the calculations above (Eq. 4). The noise in the measurement of water vapour adds additional random noise to the corrected mole fraction relative to the uncorrected mole fraction. By straightforward propagation of errors in Eq. (4), this noise can be shown to be

$\sigma_{\mathrm{corr}} \sim \sqrt{\left(\frac{-c_{\text {wet }}\left(a+2 b H_{\text {rep }}\right)}{\left(1-a H_{\text {rep }}-b H_{\text {rep }}^{2}\right)^{2}}\right)^{2}} \sigma_{H_{\text {rep }}}$

or about $0.017 \mathrm{ppm}$ for $\mathrm{CO}_{2}$ and $\sim 0.081 \mathrm{ppb}$ for $\mathrm{CH}_{4}$, using the instrument noise specification of $0.003 \%$ for water on the 5 min measurement, and nominal values for $\mathrm{CO}_{2}$ and $\mathrm{CH}_{4}$ of $400 \mathrm{ppm}$ and $1800 \mathrm{ppb}$, respectively, and a water vapour level of $3 \%$. This noise, added in quadrature to the instrument noise of $0.050 \mathrm{ppm}$ and $0.22 \mathrm{ppb}$ for $\mathrm{CO}_{2}$ and $\mathrm{CH}_{4}$, respectively, does not significantly affect the performance of the instruments relative to the GAW targets or the uncorrected measurements.

We do highlight two important assumptions inherent in this analysis. First, we have assumed that the correction due to water is proportional to the concentration of the analyte species (i.e., $\mathrm{CO}_{2}$ or $\mathrm{CH}_{4}$ ) - that is, that there is no direct absorption due to water vapour in the spectral regions of $\mathrm{CO}_{2}$ and $\mathrm{CH}_{4}$ that causes a systematic bias in the fits for those two gases even at zero $\mathrm{CO}_{2}$ and $\mathrm{CH}_{4}$ concentration. Second, we have assumed that there is no cross-interference from carbon dioxide and methane to the water vapour measurement, which would cause cross-species contamination and concentration dependence in the correction factors. We will examine these assumptions in greater detail in the laboratory results section, below. Next, in the experimental section, we discuss several experimental techniques for determining the constants $a$ and $b$ in Eq. (4).

\section{Experimental techniques for determining the water vapour correction factors}

Experimentally, to determine the constants in Eq. (4), one must devise a reliable and simple methodology for generating a gas sample that has constant (or varying but known) and nonzero dry mole fraction of carbon dioxide and/or methane, but with variable humidity. There are many possible and functionally equivalent solutions to this problem. In this section, we describe two separate methodologies that have been performed independently at MPI (Max Planck Institute for Biogeochemistry in Jena, Germany), NOAA/ESRL (NOAA Earth System Research Laboratory, Boulder, Colorado), LSCE (Laboratoire des Sciences du Climat et l'Environnement in Gif sur-Yvette, France), Empa (Swiss Federal Laboratories for Materials Testing and Research, Duebendorf, Switzerland) and Picarro, Inc. (Santa Clara, CA). 


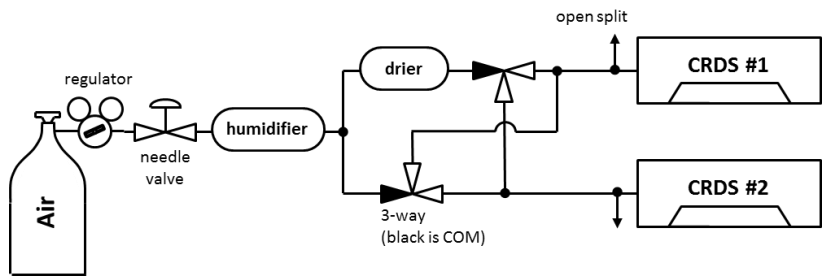

Fig. 1. Schematic for the setup of Method \#1, used by MPI-Jena, NOAA, and LSCE.

\subsection{Method \#1 - switching between wet and dry gas streams}

\subsubsection{MPI implementation}

The wet and dry mole fractions of $\mathrm{CO}_{2}$ and $\mathrm{CH}_{4}$ of a humidified gas stream can be obtained when the gas stream is alternately provided to one or more CRDS analysers through two paths, one with a chemical dryer and the other without. This method relies on the ability to generate a humidified gas stream with rather constant mole fractions of $\mathrm{CO}_{2}, \mathrm{CH}_{4}$ and $\mathrm{H}_{2} \mathrm{O}$ during each of multiple time steps. The wet/dry ratios of $\mathrm{CO}_{2}$ and $\mathrm{CH}_{4}$ are then calculated for each water vapour level. This method has been described elsewhere (Chen et al., 2010; Nara et al., 2012). A detailed description of this method as implemented at MPI is given by Chen et al. (2010) and a variant of the setup is shown in Fig. 1. To produce humidified gas samples with varying water vapour mole fractions, dry air from a tank (compressed ambient air) was provided to a dew point generator (LI-COR model 610, Lincoln, Nebraska, USA) with varying dew point settings. Water concentrations delivered by this system were $0.6-6 \%$ (for the instrument reported in Chen et al., 2010) and 0.6 to $\sim 3 \%$ for the other instruments described below. A magnesium perchlorate dryer was used to deliver the dry gas stream. The flow and pressure were carefully balanced between the two paths so that the pressure at the chemical dryer was not changing when switching the flow between the two instruments, which eliminated the possible modification of $\mathrm{CO}_{2}$ mole fractions. The whole experiment can be performed in a temperature controlled room to avoid condensation of water vapour on the surface of the inlet tubes.

The advantage of this method is that wet/dry ratios of $\mathrm{CO}_{2}$ and $\mathrm{CH}_{4}$ can be accurately determined for a series of water vapour levels that may be chosen to be evenly distributed over the experimentally realized range. Cycles of, for example, $20 \mathrm{~min}$ (10 min wet and $10 \mathrm{~min}$ dry) can be used, and for each wet air measurement, the $\mathrm{CO}_{2}$ and $\mathrm{CH}_{4}$ values of dry air measurements immediately before and after is interpolated in the analysis to provide wet/dry ratios. However, only discrete experimental points can be obtained, and no data are available for water vapour levels below $0^{\circ} \mathrm{C}$ dew point, due to the limitation of the dew point generator used in the experiment.

\subsubsection{LSCE implementation}

The experimental setup used at LSCE is substantially similar to this setup, with the exception that a single instrument was used, and the measurements were performed in a room with the standard laboratory air-conditioning set to $30^{\circ} \mathrm{C}$. A commercial dew point generator (LI-COR 610, Lincoln, Nebraska, USA) was used to humidify a dry working standard to $25^{\circ} \mathrm{C}$ dew point, using deionized water (Milli-Q, Milllipore, Billerica, Massachusetts, USA) that was not acidified, and a magnesium perchlorate dryer was used to generate the dry gas stream. The inlet to the instrument was alternated between the humid and dry gas streams.

\subsubsection{NOAA implementation}

The NOAA/ESRL lab has set up a slightly different approach to get a steady-state value of water vapour by using a gas permeable membrane device (MicroModule Contactor, LiquiCel Membrane Contactors, Membrana, Charlotte, NC, USA) in which slightly acidified water $(\mathrm{pH} \sim 5)$ resides on the shell side of the micromodule while standard air flows through the lumen side. The micromodule temperature is controlled between 2 and $30^{\circ} \mathrm{C}$ (by immersing it in a temperature controlled water bath) to obtain water vapour values ranging from 0.7 to $4.2 \%$ The flow rate of the standard gas through the membrane is regulated by the upstream pressure from the standard tank regulator. Overflow gas is vented so that ambient pressure is maintained at the analyser inlet and in the micromodule itself. This methodology can be run in the configuration suggested in Fig. 1, but has the added advantage that it can be used to slowly vary the water vapour concentration over the specified range using subtle changes in water bath temperature and standard gas flow rate. Lower water vapour concentrations (down to fully dry) are also easily achieved by using a simple plumbing and valve arrangement to blend dry tank air with some of the wetted air from the micromodule.

\subsubsection{Method \#1 discussion}

Because the dry mole fractions of gases are directly checked on the same analyser, method \#1 provides an accurate way of determining wet/dry ratios. One advantage of this method, in addition to its conceptual simplicity, is that the concentration of water vapour can be set to specific values in a controlled fashion, at least within the operating range of the dew point generator used for these measurements. Because measurements of the wet and dry samples are made simultaneously, this method also provides a robust way of ensuring that the act of humidifying the gas does not also affect the dry-mole fraction of the gas. Other methods that dry a filter or membrane, such as method \#2, below, make this assessment more difficult. In addition to requiring a dedicated dew point generator, one potential problem with this method is that the water used to humidify the standard can have a variable amount of 


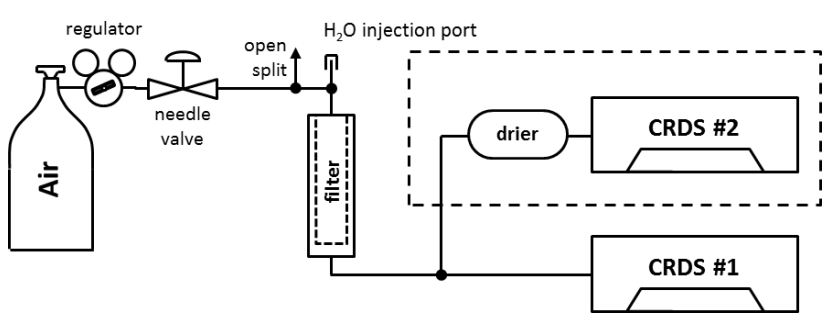

Fig. 2. Schematics of the setup for Method \#2 (NOAA/MPI implementation). The water droplet is injected through a tee connector before the hydrophobic membrane filter. The components enclosed in a dashed rectangle are optional, and are used to verify the droplet method.

carbon dioxide dissolved in the liquid (or in carbonate form), which can be released into the gas phase during the course of the experiment. For this reason, it is necessary to frequently check the dry mole fraction during the measurement to track this potential bias. Further, the method is somewhat cumbersome and therefore difficult to implement in a field setting.

\subsection{Method \#2 - water droplet method}

For the water droplet method, a working standard is humidified by passing it over a water droplet in a vessel. Each laboratory involved in this research has developed slightly different implementations of method \#2, which are described in detail below.

\subsubsection{MPI/NOAA implementations}

One implementation of the water droplet method is given by Winderlich et al. (2010). During a test, air is humidified when it flows through a stainless steel water trap that contains a droplet of water $(<1 \mathrm{~mL})$. The pressure in the water trap is manually adjusted to obtain varying mole fractions of water vapour while the temperature of the water trap is stabilised using an ice bath. Due to its portability, the water trap provides a feasible tool for performing the water test in the field. However, careful attention is required to eliminate the potential for contamination of the humidified gas stream.

Alternatively, a small amount of deionized water ( $\sim 0.5 \mathrm{~mL}$ ) added to the inlet line of the CRDS analyser can also humidify the gas stream and does not modify its mole fractions of $\mathrm{CO}_{2}$ and $\mathrm{CH}_{4}$, which provides an easy way of performing the water test. This apparatus is shown in Fig. 2. The water droplet added to the inlet line is held at the hydrophobic particulate filter of the analyser, through which water can pass only in the form of water vapour. Because the filter material is hydrophobic, it is not wet by the droplet and, therefore, does not present a large surface area of water that can potentially store or release $\mathrm{CO}_{2}$ into the sample stream. During a test, the water vapour mole fraction in the gas stream decreases as the water droplet is depleted. A second analyser is employed to measure dry air mole fractions

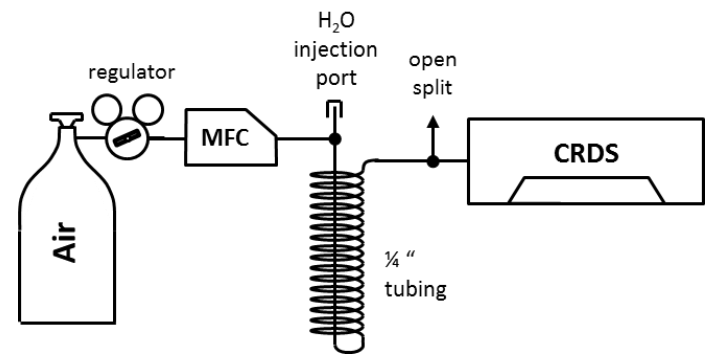

Fig. 3. Schematic for the setup of Method \#2 (Empa implementation).

simultaneously to check any potential influences of injected water on $\mathrm{CO}_{2}$ and $\mathrm{CH}_{4}$. Laboratory tests show that within the noise levels, water droplets made of deionized or acidified deionized water do not modify the $\mathrm{CO}_{2}$ and $\mathrm{CH}_{4}$ mole fractions, where those made of tap water could modify the $\mathrm{CO}_{2}$ mole fractions up to a few tenths of ppm (see the supplementary material for details). In addition, it has been found that dry mole fractions of $\mathrm{CO}_{2}$ in the first 2-3 min after injection of water droplet are enhanced by a few tenths of ppm (confirmed by measurements by the CRDS analyser with a dryer). The cause of this small enhancement has not been identified. We suggest discarding this period unless the dry values are independently measured with a second instrument.

This water droplet test often results in abrupt change of water vapour mole fractions, and it provides sparse measurements in certain water vapour ranges. The sparseness of water vapour measurements introduces errors that are associated with the interpolation of water vapour measurements to the times when $\mathrm{CO}_{2}$ and $\mathrm{CH}_{4}$ measurements are made, and contributes to the uncertainty of derived water corrections. To obtain slowly changing water vapour mole fraction, a small amount of silica gel soaked with deionized or acidified water has been used at NOAA/ESRL to humidify the gas stream. In practice, the silica gel was housed in a stainless steel filter (Swagelok, SS-2F-2, Solon, OH, USA) with the internal elements removed. Plastic instead of stainless steel connectors may be utilised to connect the filter to the inlet of the analyser to avoid additional $\mathrm{CH}_{4}$ from metal-metal friction.

\subsubsection{Empa implementation}

In the Empa set-up (Fig. 3, and described in Zellweger et al., 2012), water is injected into a piece of 1/4 inch Synflex 1300 tubing which is shaped to a coil in order to prevent water from entering the instrument. The pressure remains constant at roughly atmospheric pressure for the duration of the experiment. For these experiments, approx. $0.8 \mathrm{~mL}$ ultrapure water was injected into a dry standard gas flowing at rate of $500 \mathrm{~mL} \mathrm{~min}^{-1}$. Such an experiment usually takes approximately $2 \mathrm{~h}$, and there is enough conditioning time at the beginning of the experiment to allow for equilibration. Usually, the first data during the saturation phase have to be discarded. 

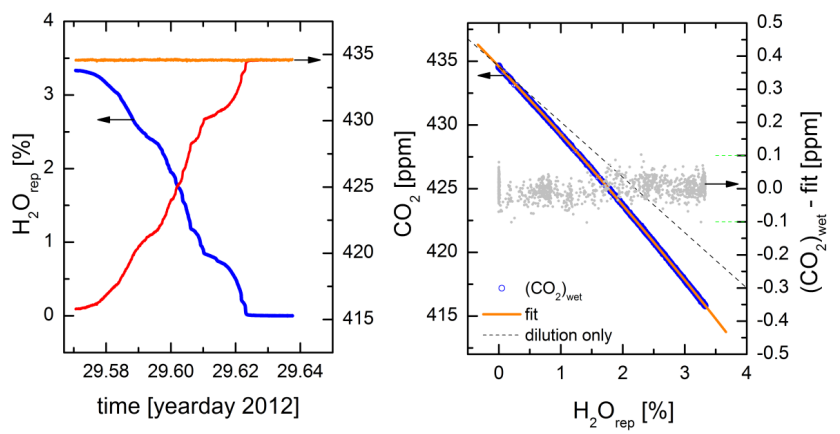

Fig. 4. Left: example of $\mathrm{CO}_{2}$ and $\mathrm{H}_{2} \mathrm{O}$ measured during a water vapour interference experiment as described above for a $\mathrm{G} 2401$ analyser. The red data are 1 min-averages of the raw $\mathrm{CO}_{2}$ data reported the instrument, and the orange curve displays the water vapour corrected $\mathrm{CO}_{2}$ data based on the fitting parameters determined by this experiment. Right: experimentally derived $\left(\mathrm{CO}_{2}\right)_{\mathrm{wet}}$ (blue circles) vs. water reported mole fractions and fitted correction function (orange). Residuals from the fit (gray points) are shown on the right axis, along with the WMO/GAW goals (green dashed lines).

The water vapour range that is covered by this set-up ranges from 0 to approximately $2.8 \%$ at $23^{\circ} \mathrm{C}$ and 1 bar. A further advantage of this set-up is that the water vapour range is completely covered. The resulting water vapour concentrations and carbon dioxide mole fractions are shown in the left panel of Fig. 4, and the resulting fit of the data to the water vapour correction function are shown in the right panel, along with the fit residuals. It is important to note that the uncertainty in the fit coefficients due to the inherent noise of the instrument is always a factor of 10 or more smaller than the repeatability of the measurement on a given instrument on a given day. In other words, the uncertainty in the determination of the water correction factors is not dominated by instrument noise, but instead by the experimental biases inherent to the methodologies.

\subsubsection{LSCE implementation}

In the LSCE version of the setup, a $0.2 \mathrm{~mL}$ droplet of ultrapure water is injected into a hydrophobic filter (M\&C LB-1SS) located upstream of the inlet to the instrument. Delivery pressure of the dry standard gas is about $0.2 \mathrm{bar}(\mathrm{g})$. As in the other methods, the experiment continues until the droplet is completely evaporated. Dry values are measured before the water droplet injection and are checked after the droplet evaporation. The first two to three minutes following the water injection are discarded for the final calculations. The filter may be heated to generate water vapour levels above the ambient dew point in the laboratory, even above $5 \%$ water vapour. Experiments usually take $1-2 \mathrm{~h}$, the time it takes for the droplet to evaporate under typical laboratory conditions. They are usually repeated three times to have

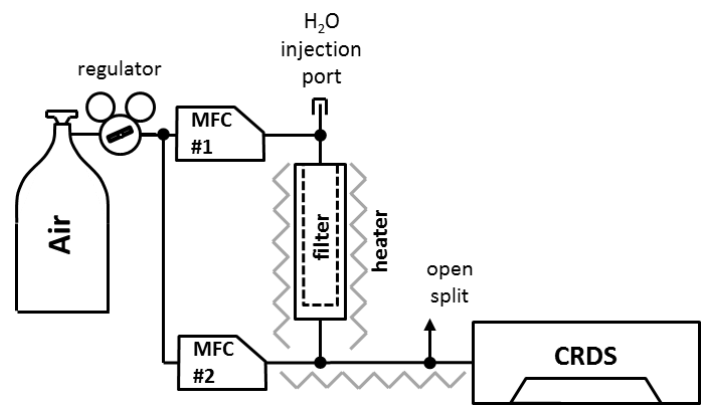

Fig. 5. Schematic for the setup of Method \#2 (Picarro implementation).

sufficient experimental data points and to guarantee a more robust correction assessment.

\subsubsection{Picarro implementation}

In the Picarro implementation (Fig. 5), two mass flow controllers (Smart Trak 50 Series, C50L-SS-DD-1-PV2-V0-F1, Sierra Instruments, Monterey, CA, USA) are added to the LSCE implementation. One mass flow controller (MFC) is situated upstream of the hydrophobic filter, and the second MFC is used to dilute the flow of humid air exiting the hydrophobic filter. The filter can be heated above ambient temperature to allow measurements at elevated dew points, and the plumbing downstream of the filter is heated to above the filter temperature to ensure that water vapour does not condense in the transfer lines. By varying the ratios of the flows through MFCs, one can generate an arbitrary water vapour concentration profile in the instrument until the water droplet fully evaporates (although the concentration delivered by this system is not targeted as well as with a dew point generator), which reduces the potential for bias associated with the emission or uptake of carbon dioxide from the water droplet as the droplet evolves.

\subsubsection{Method \#2 discussion}

The various implementations of Method \#2 all have the advantage that they relatively easy to deploy, which makes this method attractive for in-situ testing of the water vapour correction factors. The accuracy in the water corrections determined from this method, especially for $\mathrm{CO}_{2}$, depends on the integrity of the assumed dry mole fractions and the measured mole fractions of the humidified gas for $\mathrm{CO}_{2}$ and $\mathrm{CH}_{4}$ by the CRDS analyser. Usually the dry mole fractions are measured before and after the water droplet test, and the difference should be sufficiently small, e.g., below $0.05 \mathrm{ppm}$, to exclude potential biases caused by insufficiently flushed pressure regulators or an unwanted leak. Besides the effect that mole fractions of $\mathrm{CO}_{2}$ are slightly enhanced by a few tenths of ppm immediately after a water droplet is injected, any contamination in sampling system may cause a potential 


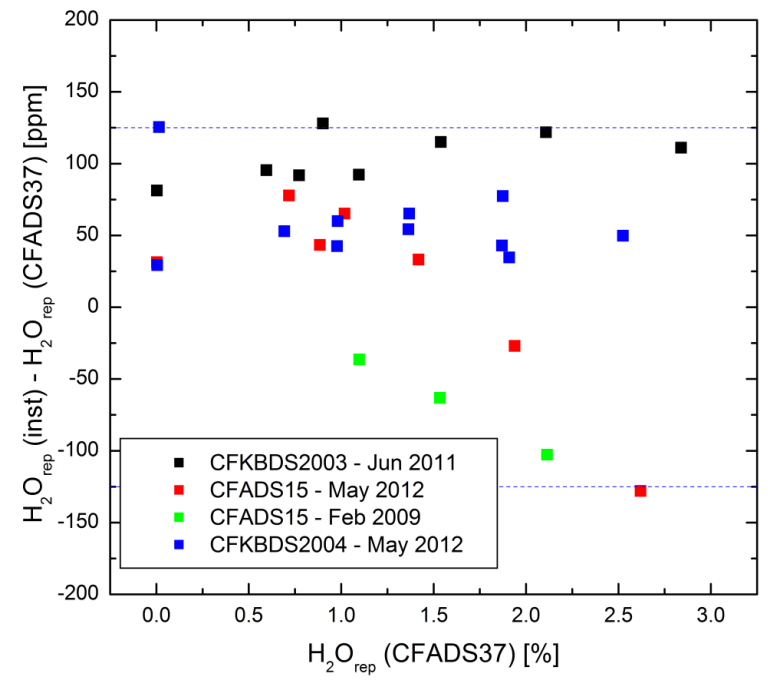

Fig. 6. Water vapour comparisons between the analysers indicated in the legend and the CFADS37 analyser. Shown are the differences of $\left(\mathrm{H}_{2} \mathrm{O}\right)_{\text {rep }}$ from the respective analyser and the CFADS37, against the $\left(\mathrm{H}_{2} \mathrm{O}\right)_{\text {rep }}$ from the CFADS37 analyser. The dashed lines indicate the $125 \mathrm{ppm} \mathrm{H}_{2} \mathrm{O}$ differences.

bias for $\mathrm{CO}_{2}$ and $\mathrm{CH}_{4}$ as well. By using a very small volume of liquid water (typically $0.2-0.8 \mathrm{~mL}$ ), and by using distilled (deionized) and/or slightly acidified water, the effects of dissolved carbon dioxide can be reduced relative to the larger water volumes associated with dew point generators. However, the possibility for bias due to carbon dioxide dissolved in the water remains a concern and a potential source of bias with this method. In addition, the simpler implementations of the droplet method allow for no control over the water vapour level delivered to the instrument, although this problem can be solved by varying the pressure or a dilution flow, at the cost of complexity. Finally, the pressure-variation alternative has the additional disadvantage that the head pressure above the liquid water is varied, which can lead to carbon dioxide either being outgassed or dissolved by the liquid sample.

\section{Laboratory validation and discussion}

\subsection{MPI/NOAA results}

\subsubsection{Repeatability of water vapour measurements}

Key to being able to correct for the effect from water vapour in a wet air measurement is the precise and stable measurement of water vapour. To assess the stability of the CRDS water vapour measurements over time, different pairs of analysers at different times were exposed to the same gas stream (humidified calibration gas) for the water vapour range of $0-3 \%\left(H_{\text {rep }}\right)$, and the readings were compared. Figure 6 shows the comparisons of three different analysers against the CFADS37 analyser. The two comparisons between CFADS15 and CFADS37 were performed with more than three years separation, and indicate a good longterm stability. The largest differences in the reported $\mathrm{H}_{2} \mathrm{O}$ are about $125 \mathrm{ppm}$, corresponding to an error in the watercorrected $\mathrm{CO}_{2}$ mole fraction of about $0.06 \mathrm{ppm}$, based on the Chen et al. (2010) correction.

This error can in principle be reduced by referring all CRDS water measurements to the same scale, i.e., to that of a single instrument. Repeated comparisons of different analysers to a single instrument has indicated differences between measurements of water vapour between the two instruments of less than about $100 \mathrm{ppm}$ in $\mathrm{H}_{2} \mathrm{O}$, which corresponds to an error in the water vapour correction for $\mathrm{CO}_{2}$ of less than $0.05 \mathrm{ppm}$.

All G1301 and G2301 instruments have used the same numerical factor to relate the height of the water vapour absorption line to the concentration of water vapour; no experiments are performed to adjust this constant from instrument to instrument, due to the difficulty of generating an accurate water vapour concentration in the laboratory. However, there is statistical information on other species, such as $\mathrm{CO}_{2}$, which allows us to estimate the variability of the water vapour scale from instrument to instrument. For a sample size of $N=23$ randomly selected instruments, the standard deviation of the slope constant is $0.22 \%$ for $\mathrm{CO}_{2}$, and all of the calibration constants are within $0.5 \%$ of the mean. Assuming that the same relative relationship holds for $\mathrm{H}_{2} \mathrm{O}$, this result implies that variation in the slope would lead to variability of $50 \mathrm{ppm}$ $\mathrm{H}_{2} \mathrm{O} / \% \mathrm{H}_{2} \mathrm{O}$. This estimate is consistent with the results of observations presented in Fig. 6. This error in the water vapour concentration propagates to the measurement of the dry mole fractions when using the Chen et al. (2010) coefficients, leading to an additional instrument-to-instrument variability of $0.024 \mathrm{ppm} / \% \mathrm{H}_{2} \mathrm{O}$ and $0.10 \mathrm{ppb} / \% \mathrm{H}_{2} \mathrm{O}$ for $\mathrm{CO}_{2}$ and $\mathrm{CH}_{4}$, respectively. These errors do not apply when instrument specific correction factors are generated, since the water scale variability is accounted for directly in the measurement method.

\subsubsection{Stability over time and transferability across multiple instruments}

Based on Method \#1 and \#2, water corrections for the $\mathrm{CO}_{2} / \mathrm{CH}_{4} / \mathrm{H}_{2} \mathrm{O}$ analyser (CFADS37) from Max Planck Institute for Biogeochemistry have been derived in February 2009, November 2010 and July 2012 to assess the longterm stability of the correction. Furthermore, a number of analysers have been evaluated, including the more recent 2000 series, to assess the transferability of the correction between different analysers. The stability of the water corrections for both $\mathrm{CO}_{2}$ and $\mathrm{CH}_{4}$ are demonstrated in Fig. 7, which shows the differences between the measured dry air mole fraction and the corrected values for the measurements in wet air for the different experiments and analysers. Note that for all analysers the Chen et al. (2010) 

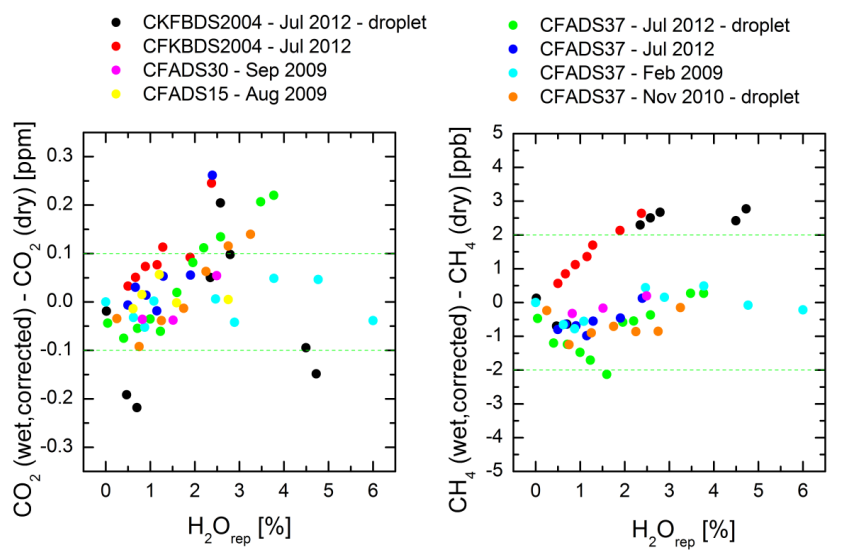

Fig. 7. Results from wet-dry experiments using method \#1 at MPI Jena for $\mathrm{CO}_{2}$ (left) and $\mathrm{CH}_{4}$ (right). Shown are differences of dry measurements and corrected wet measurements using the Chen et al. (2010) coefficients. Dashed lines indicate the compatibility goals set by the WMO (2011). Mole fractions ranged between 380 and $430 \mathrm{ppm}$ for $\mathrm{CO}_{2}$ and between 1800 and $2000 \mathrm{ppb}$ for $\mathrm{CH}_{4}$.

coefficients are used in the wet-dry correction, and all instruments use the same scale for water vapour measurements. The results shown in Fig. 7 indicate differences between corrected and actual dry air mole fractions less than $0.05 \mathrm{ppm}$ and $1 \mathrm{ppb}$ for $\mathrm{CO}_{2}$ and $\mathrm{CH}_{4}$, respectively, for the experiments with CFADS37 separated by about 3.5 years. Furthermore, the results for analysers CFADS15 and CFADS30 in Fig. 7 show similar differences, indicating full transferability of the correction at least for the range up to about $2 \%$ water vapour mole fraction. The results from a recent experiment with the CFKB2004 four-species analyser and CFADS37 (in July 2012), where up to $2 \%$ water vapour mole fraction all except for one value are within the limits given by the WMO recommended compatibility goal. Similar results have been shown for three CRDS analysers tested at NOAA/ESRL using Method \#2 (Fig. 8), which demonstrates that transferring the coefficients based on Chen et al. (2010) to the three analysers causes an error less than $0.1 \mathrm{ppm} \mathrm{CO}_{2}$ and less than $2 \mathrm{ppb}$ for $\mathrm{CH}_{4}$ for up to $3 \%$ water vapour mole fraction. Note that the water vapour measurements have not been crossreferenced to each other. The differences at low water vapour mole fractions may be due to the small differences between the three analysers and the one tested by Chen et al. (2010).

\subsection{LSCE results - repeatability in the determination of the correction factors using different methods on a single instrument}

Over a period of twenty days, the correction factors were determined on a single instrument with multiple trials of methods \#1 and \#2. The differences between these correction factors relative to the values described in Chen et al. (2010) are shown in Fig. 9, for nominal levels of 400 and $1900 \mathrm{ppb}$ for $\mathrm{CO}_{2}$ and $\mathrm{CH}_{4}$, respectively. The repeated trials appear

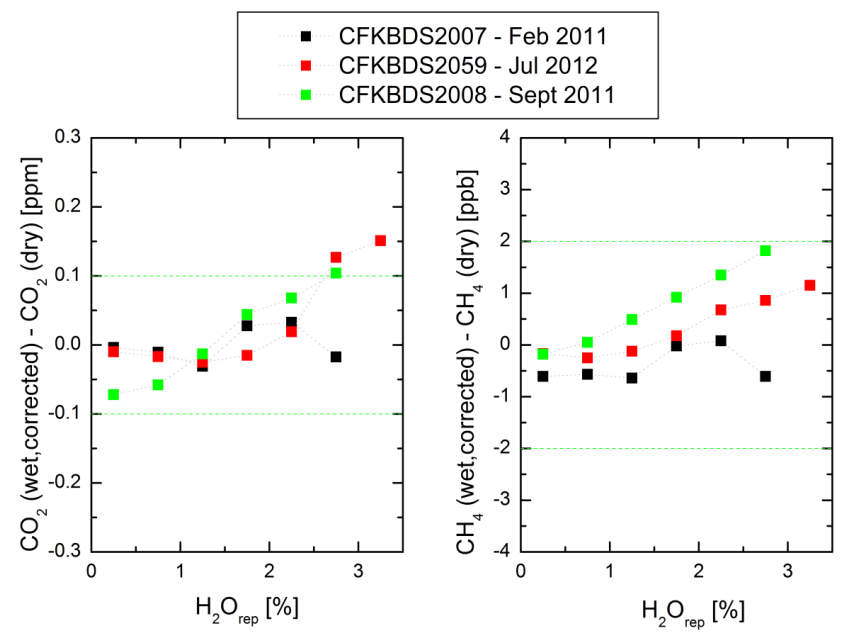

Fig. 8. Results from water droplet tests at NOAA Boulder for $\mathrm{CO}_{2}$ (top) and $\mathrm{CH}_{4}$ (bottom). Shown are differences of dry measurements and corrected wet measurements using the Chen et al. (2010) coefficients (without rescaling water vapour). Different symbols indicate different instruments. Dashed lines indicate the compatibility goals set by the WMO (2011). Mole fractions ranged between 360 and $390 \mathrm{ppm}$ for $\mathrm{CO}_{2}$ and between 1700 and $1900 \mathrm{ppb}$ for $\mathrm{CH}_{4}$.

to lead to a significant spread in the corrected values, although we note that all values are within the GAW compatibility targets up to $2 \%$ water vapour for $\mathrm{CO}_{2}$ and $4 \%$ water vapour for $\mathrm{CH}_{4}$, and the range for $\mathrm{CO}_{2}$ increases to $4 \%$ if one of the humidifier tests is eliminated as an outlier. The root cause of this outlier has not been identified. This result clearly points to the fact that the different methodologies are all capable of producing high-quality results, but that the confidence in the results can be increased by performing multiple measurements.

\subsection{Empa results - stability over time and transferability across multiple instruments}

At Empa, the water correction factors were determined using Method \#2 on a single instrument (CFADS49) over a period of 18 months. The results of these repeated measurements are shown in Fig. 10, where the difference between the first measurement and the subsequent five measurements are shown, along with the GAW compatibility targets. The correction factors produce dry mole fraction results that are within the GAW compatibility targets up to 2 and $4 \%$ water vapour for $\mathrm{CO}_{2}$ and $\mathrm{CH}_{4}$, respectively. Note that this result is a combined uncertainty that captures the errors in Method \#2 as implemented at Empa, as well as drift in the instrument over time.

Similarly, one may compare the correction factors determined on multiple instruments. These results are shown in Fig. 11, along with the values described in Chen et al. (2010). As is clear from the figures, the transferability of the correction factors between instruments extends to about $1 \%$ 


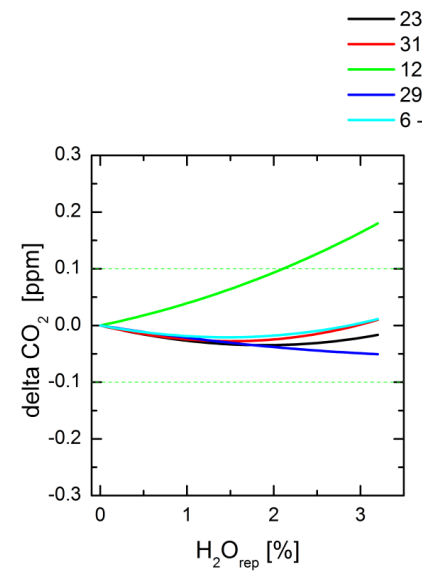

$$
\begin{aligned}
& 23 \text { - May droplet } \\
& 31 \text { - May droplet } \\
& 12 \text { - Jun humidifier } \\
& 29 \text { - May droplet }
\end{aligned}
$$

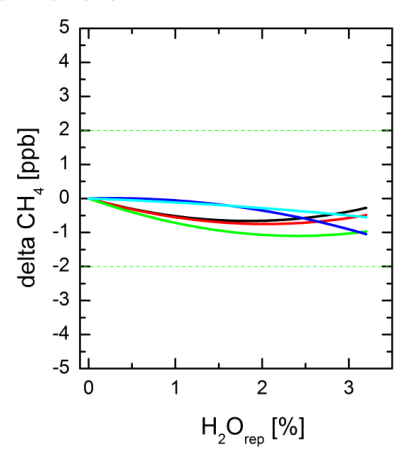

Fig. 9. Deviations between the correction factors determined on a single instrument over 20 days and 5 replications at LSCE using methods \#1 and \#2, and the values reported in Chen et al. (2010). Left panel: $\mathrm{CO}_{2}$ measured at $400 \mathrm{ppm}$. Right panel: $\mathrm{CH}_{4}$ measured at $1900 \mathrm{ppb}$. The WMO/GAW targets are indicated by the green dashed lines in both panels.
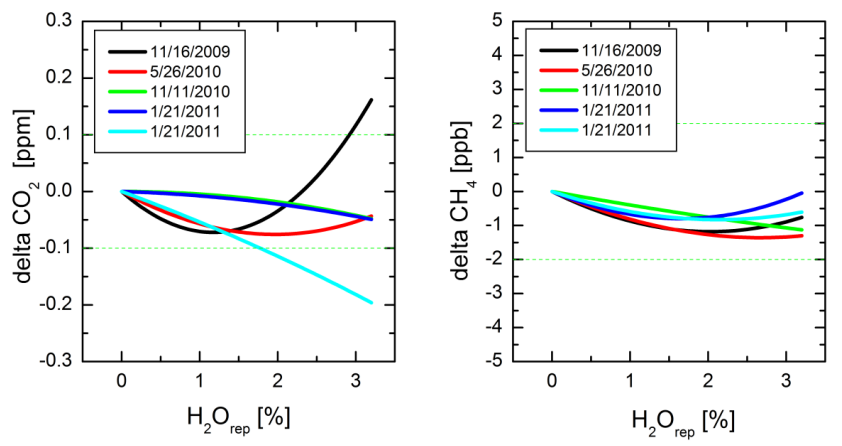

Fig. 10. Correction factors for a single G1301 instrument at Empa for $\mathrm{CO}_{2}$ (left panel) and $\mathrm{CH}_{4}$ (right panel) calculated for mole fractions of $400 \mathrm{ppm} \mathrm{CO} 2$ and $1900 \mathrm{ppb} \mathrm{CH}_{4}$ over a period of 18 months, plotted as a deviation against the initial determination of the correction on 22 July 2009.

water vapour for both $\mathrm{CO}_{2}$ and $\mathrm{CH}_{4}$. This result highlights the point that using a single set of coefficients for all instrumentation leads to GAW-quality results at low to moderate humidity levels, but that at high humidity levels, it is strongly encouraged that the correction functions be determined for each individual instrument independently. In addition, regular repetitions of the experiment are recommended to quantify the correction functions over time.

\subsection{Uncertainty analysis}

As we have seen in the above sections, measurements of the wet-dry correction coefficients for $\mathrm{CO}_{2}$ and $\mathrm{CH}_{4}$ have been performed by multiple laboratories on multiple instruments. Taken as a whole, these data provide an opportunity for applying statistical analysis methods to arrive at robust esti-
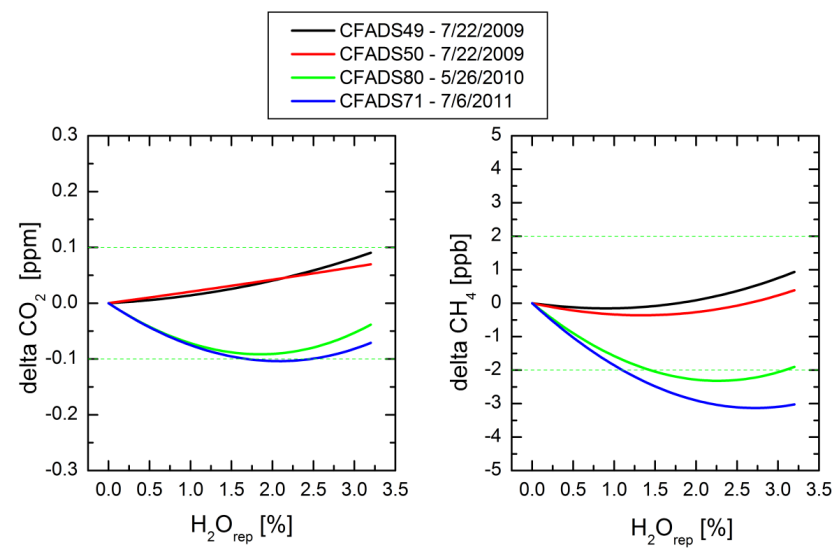

Fig. 11. Dry mole-fraction corrections for several instruments at Empa calculated for mole fractions of $400 \mathrm{ppm} \mathrm{CO}_{2}$ and $1900 \mathrm{ppb}$ $\mathrm{CH}_{4}$, compared against the coefficients from Chen et al. (2010), indicating instrument transferability of the correction coefficients.
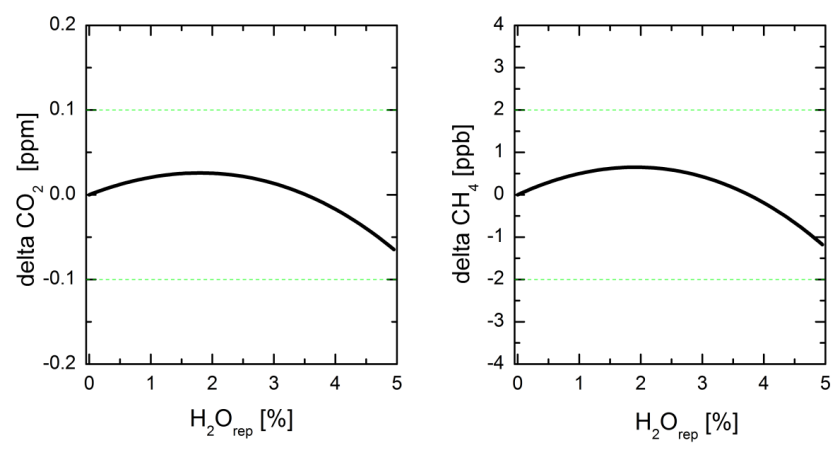

Fig. 12. Calculated difference between the corrections based on Chen et al. (2010), and the mean values based on the distribution of all the data for $\mathrm{CO}_{2}$ (left panel) and $\mathrm{CH}_{4}$ (right panel), as a func-

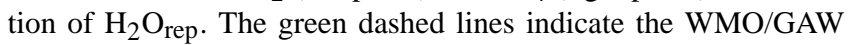
targets.

mates of the uncertainties of the wet-dry correction. A total of twenty-nine measurements were made at four different laboratories (MPI-Jena, NOAA, Empa and LSCE) on thirteen different instruments (either G1301, G2301 or G2401 models) over a period of four years. Ranges for $\mathrm{CO}_{2}$ and $\mathrm{CH}_{4}$ for these experiments are 360-550 ppm and 1700-2300 ppb, respectively. Table 1 lists the means and standard deviations for the four coefficients $a-d$ :

These twenty nine measurements (which include the measurements used in Chen et al., 2010) provide a useful validation of the coefficients reported in Chen et al. (2010). In Fig. 12, we plot the difference between the mean values for the coefficients and the values from Chen et al. (2010). Even above $4 \% \mathrm{H}_{2} \mathrm{O}$, the two correction factors agree, well within the WMO compatibility goals. The majority of the tests were not performed above $4 \%$ water vapour, so it is not surprising that the correction equations begin to diverge at these levels. 

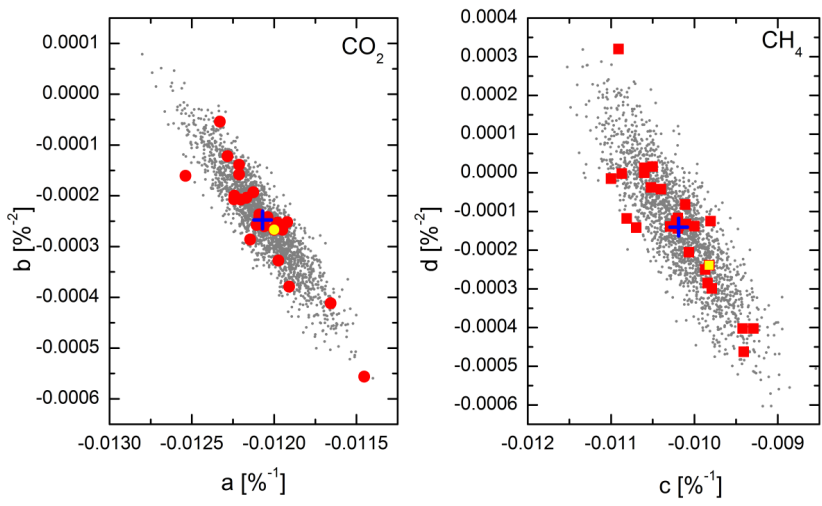

Fig. 13. Distribution of empirically determined correction coefficients (red points) for $\mathrm{CO}_{2}$ (left panel) and $\mathrm{CH}_{4}$ (right panel) at LSCE, NOAA, MPI-Jena, and Empa. Also shown in both panels are the values from Chen et al. (2010) (yellow points), and the means of each distribution (blue crosses). The gray points represent the Monte Carlo simulation $(N=2000)$ of the coefficients as modelled by a bivariate Gaussian distribution (see text for more information). Fig. 14: Uncertainty analysis based on the Monte Carlo simulation $(N=2000)$ of the correction coefficients. The grey area indicates the uncertainty $(1-\sigma)$ introduced by using the Chen et al. (2010) coefficients on any given instrument. The purple hashed area indicates the uncertainty introduced by a single measurement of the correction coefficients when the instrument is deployed. Finally, the blue hashed area indicates the overall repeatability of the measurement methodologies described in this paper. See the text for more information.

A simple way to approach the uncertainty estimate would be to cascade the standard deviations of the individual coefficients through the correction equations to arrive at an overall uncertainty. However, this method might either over or under estimate the errors, depending on the degree of covariance between the parameters. For example, if $a$ exhibits a positive correlation with $b$, then the errors in the individual coefficients are magnified. Conversely, if $a$ is negatively correlated with $b$, then the errors are minimised.

In Fig. 13, we plot the correlation between $a$ and $b$ and between $c$ and $d$. In both cases, there is a strong anti-correlation between the two parameters, indicative of a compensating effect where a more negative slope is counterbalanced (at least in part) by a more positive quadratic term.

To determine the major and minor axes of the observed distribution of parameters, we analyse these data via Principal Component Analysis (PCA) (Shlens, 2009). The covariance matrix is defined as follows for $\mathrm{CO}_{2}$ (the treatment is analogous for $\mathrm{CH}_{4}$ ):

$c_{a b}=\left[\begin{array}{cc}\sigma_{a}^{2} & \sigma_{a b}^{2} \\ \sigma_{a b}^{2} & \sigma_{b}^{2}\end{array}\right]$
Table 1. Average correction coefficients based on measurements made at NOAA, MPI, LSCE and Empa, along with the values from Chen et al. (2010) for reference. Note that the test in Chen et al. (2010) was performed up to $6 \%$ reported water vapour, whereas majority of these tests were performed below $4 \%$.

\begin{tabular}{ccc}
\hline Parameter & Mean and standard dev. & Chen et al. (2010) \\
\hline$a$ & $-1.207 \times 0.0197 \times 10^{-2}$ & $-1.200 \times 10^{-2}$ \\
$b$ & $-2.475 \times 0.910 \times 10^{-4}$ & $-2.674 \times 10^{-4}$ \\
$c$ & $-1.019 \times 0.0453 \times 10^{-2}$ & $-0.982 \times 10^{-2}$ \\
$d$ & $-1.404 \times 1.539 \times 10^{-4}$ & $-2.390 \times 10^{-4}$ \\
\hline
\end{tabular}

Where $\sigma_{a}^{2}$ and $\sigma_{b}^{2}$ are the variances of the data set calculated in the normal manner, and the covariance is defined by $\sigma_{a b}^{2}=\frac{1}{N-1} \sum_{N}\left(a_{i}-\bar{a}\right)\left(b_{i}-\bar{b}\right)$. The eigenvectors of the covariance matrix give the orientation of the major and minor axes of the bivariate normal (i.e., Gaussian) distribution, and the eigenvalues of this matrix give the variances along these axes. The results of the PCA are shown in Table 2. Note that the orientation of the major axis captures the anti-correlation of $a$ and $b$, and $c$ and $d$ :

Using this distribution of parameters, we have performed a Monte Carlo simulation of two thousand possible pairs of parameters for each gas, using the bivariate normal distributions centred on the mean and rotated to lie along the major and minor axes. These distributions for $a, b$ and $c, d$ are also shown in Fig. 13. Then, using Eq. (4), we compute the difference between the correction given by each of these parameter pairs and the correction provided by the canonical values from Chen et al. (2010), for nominal concentrations of $400 \mathrm{ppm}$ and $1900 \mathrm{ppb}$ for $\mathrm{CO}_{2}$ and $\mathrm{CH}_{4}$, respectively. The mean and standard deviation of the resulting difference is analysed as a function of water vapour concentration, and the results are shown in Fig. 14 (where the one sigma limits around the mean value are shown by the grey area). We interpret the grey area as the distribution of error in the correction factor across the population of instruments if the Chen et al. (2010) values are used in the correction expression. For $\mathrm{CO}_{2}$, we find that for $\mathrm{H}_{2} \mathrm{O}$ concentrations below about $0.6 \%$ we expect that using the Chen et al. (2010) correction for any instrument would have an uncertainty of $\pm 0.05 \mathrm{ppm}(1 \sigma)$, and up to $2 \%$, we expect that using the Chen et al. (2010) correction would have an uncertainty of $\pm 0.1 \mathrm{ppm}$. For $\mathrm{CH}_{4}$, the situation is similar: for $\mathrm{H}_{2} \mathrm{O}$ concentrations below about $0.9 \%$, the Chen et al. (2010) correction has an uncertainty of about $\pm 1 \mathrm{ppb}$, and below $3.4 \%$, the Chen et al. (2010) correction has an uncertainty of about $\pm 2 \mathrm{ppb}$. It is important to note, however, that any given instrument may have a set of correction factors which give a persistent bias to the correction. It is also important to point out that the divergence of the uncertainty at high water vapour concentrations is largely due to the fact that in most cases, the instruments were tested only up to about $3 \%$ water vapour. 

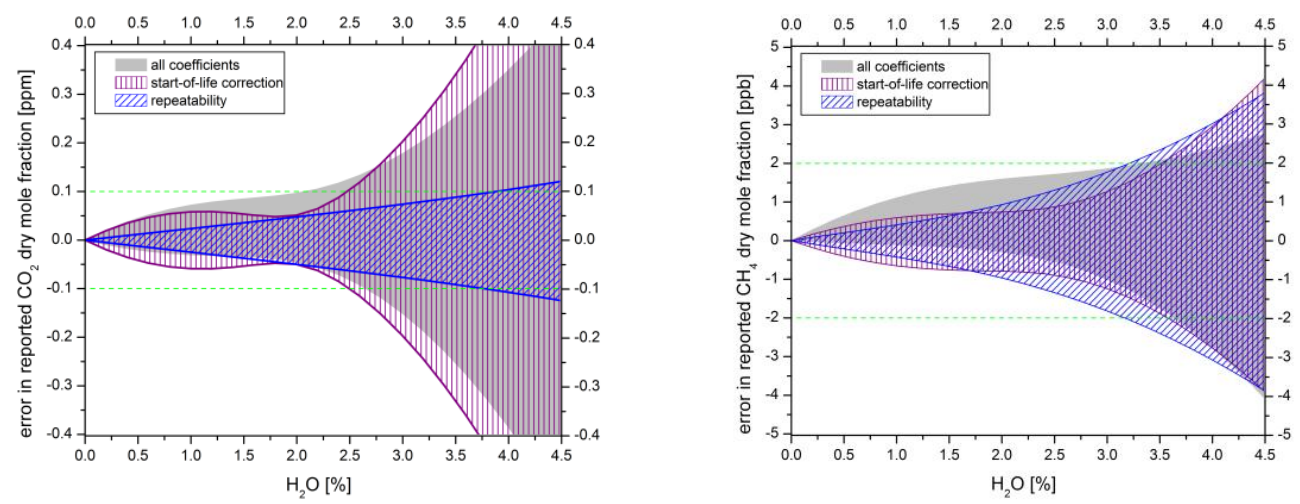

Fig. 14. Uncertainty analysis based on the Monte Carlo simulation $(N=2000)$ of the correction coefficients. The grey area indicates the uncertainty $(1-\sigma)$ introduced by using the Chen et al. (2010) coefficients on any given instrument. The purple hashed area indicates the uncertainty introduced by a single measurement of the correction coefficients when the instrument is deployed. Finally, the blue hashed area indicates the overall repeatability of the measurement methodologies described in this paper. See the text for more information.

Table 2. PCA analysis of correction factor coefficients for $\mathrm{CO}_{2}$ and $\mathrm{CH}_{4}$, giving the major and minor axes of the bivariate distributions for all the observations (all data), for the subset of observations where multiple measurements were made over time (single instrument over time), and for the subset of observations made on a single instrument within a short period of time (repeatability).

\begin{tabular}{lcr}
\hline Gas & Std. dev. along major/minor axes & Major axis unit vector \\
\hline $\mathrm{CO}_{2}-$ all data & $2.14 \times 10^{-4} / 3.72 \times 10^{-5}$ & $(0.918,-0.394)$ \\
$\mathrm{CO}_{2}-$ single instrument over time & $3.03 \times 10^{-4} / 2.71 \times 10^{-5}$ & $(0.897,-0.441)$ \\
$\mathrm{CO}_{2}-$ repeatability & $0.62 \times 10^{-4} / 0.82 \times 10^{-5}$ & $(0.999,-0.05)$ \\
$\mathrm{CH}_{4}$ - all data & $4.73 \times 10^{-4} / 7.63 \times 10^{-5}$ & $(0.958,-0.286)$ \\
$\mathrm{CH}_{4}$ - single instrument over time & $5.37 \times 10^{-4} / 6.71 \times 10^{-5}$ & $(0.938,-0.347)$ \\
$\mathrm{CH}_{4}-$ repeatability & $2.46 \times 10^{-4} / 9.09 \times 10^{-5}$ & $(0.982,-0.191)$ \\
\hline
\end{tabular}

We have performed a similar Monte Carlo simulation on two other subsets of the data:

1. Those instruments for which multiple measurements were made over time can be used to establish the uncertainty in the correction when instrument-specific correction factors are used (CFADS37, CFADS49 and CFADS50). For these instruments, the initial determination of the correction factors are used for comparison of subsequent measurements of the correction factors, rather than the coefficients from Chen et al. (2010). The results of the PCA analysis is shown in Table 2, in the rows labelled "single instrument over time". Using these bivariate normal distributions, a Monte Carol simulation was performed, and the resulting uncertainty of expected correction values $(1 \sigma)$ are shown in the purple hashed areas of Fig. 14. Note that the distributions are now centred about zero, due to the fact that the measurement of the instrument specific correction factors centres the uncertainty distribution around zero, with no persistent bias. In addition, the use of instrumentspecific correction factors reduces the uncertainty distribution for both $\mathrm{CO}_{2}$ and $\mathrm{CH}_{4}$ significantly in the 2$3 \%$ range, by nearly a factor of two for both gases.
For $\mathrm{H}_{2} \mathrm{O}$ below $2.1 \%$, the uncertainty in the $\mathrm{CO}_{2}$ correction is less than $\pm 0.06 \mathrm{ppm}(1 \sigma)$, and for $\mathrm{H}_{2} \mathrm{O}$ below $2.7 \%$, the uncertainty in $\mathrm{CH}_{4}$ is less than $\pm 1 \mathrm{ppb}$ $(1 \sigma)$. The fact that the uncertainty distribution narrows significantly when using an instrument specific correction factor indicates that at least some of the observed variability in the coefficients is due to instrument-toinstrument variability; i.e., that means that there is no single set of coefficients that could be applied equally well to all instruments.

2. Those instruments for which multiple measurements were made at a specific time can be used to establish the overall repeatability of the methodology (CFADS49 and CFKADS2022, $N=7$ measurements total). In this case, the mean of the multiple measurements on each instrument are used as a point of comparison, rather than the coefficients of Chen et al. (2010). The PCA analysis for this data set is shown in Table 2 in the rows labelled "repeatability", and the resulting uncertainty of expected correction values $(1 \sigma)$ are shown in the blue hashed areas of Fig. 14. This area represents the repeatability of a single measurement of the correction factors using the methodologies described above. Clearly, this 
uncertainty represents a significant error, especially at high water vapour concentrations, although the data set informing this analysis was limited. This relatively large uncertainty certainly contributes to the uncertainties of the corrections, and points to the need for repeated measurement of the correction factors at the start of life to reduce this uncertainty. We note that repeated measurements can be used to provide instrument-specific correction factors as a function of time. This uncertainty can be reduced from what is shown in the figures by repeated careful measurements of the correction factor over time on each instrument. Note that this uncertainty includes the noise and residuals of the measurements of the three concentrations, and any variability and biases associated with the methodologies used. It is expected that repeated measurements of the correction factor over time will lead to reduced uncertainty in the corrections to the $\mathrm{H}_{2} \mathrm{O}=4 \%$ level and beyond for both analyte gases, although the validity of this hypothesis has been yet to be demonstrated in practice. It is not clear from this uncertainty analysis whether individual instruments exhibit significant drift relative to the start of life coefficients. Additional long-term measurements of the correction coefficients are required to answer this question fully.

\subsection{Direct spectroscopic interference analysis}

In the previous sections, we have implicitly assumed that the correction to water vapour follows the simple dependence described by Eq. (4). In this section, we discuss and quantify two possible effects which could bias the dry mole calculation: direct spectroscopic interference between carbon dioxide, methane and water vapour, and the effects of stable isotopes on these measurements.

\subsubsection{Direct spectroscopic interference}

To derive Eq. (4), it was necessary to explicitly assume that the bias in the reported dry mole fractions of $\mathrm{CO}_{2}$ and $\mathrm{CH}_{4}$ measurements is zero when the water vapour concentration is zero, or when the $\mathrm{CO}_{2}$ or $\mathrm{CH}_{4}$ concentrations are zero. However, direct spectroscopic interference between the species could cause a bias in the measurements that would not follow this same functional form. To investigate this effect, the following three sets of measurements were performed:

1. Measurements where the $\mathrm{CO}_{2}$ and $\mathrm{CH}_{4}$ were zero, but the water vapour was varied over a wide range of values.

2. Measurements where water vapour and $\mathrm{CH}_{4}$ were zero, but $\mathrm{CO}_{2}$ was varied over a wide range of values.

3. Measurements where water vapour and $\mathrm{CO}_{2}$ were zero, but $\mathrm{CH}_{4}$ was varied over a wide range of values.
As a result of these measurements, we obtain the following results for the bias between different species:

$$
\begin{aligned}
\left(\mathrm{CO}_{2}\right)_{\text {bias }} & =0.0339 \mathrm{ppm} / \% \mathrm{H}_{2} \mathrm{O} \\
\left(\mathrm{CH}_{4}\right)_{\text {bias }} & =1.017 \mathrm{ppb} / \% \mathrm{H}_{2} \mathrm{O} \\
\left(\mathrm{H}_{2} \mathrm{O}\right)_{\text {bias }} & =9.1 \times 10^{-6} \% \mathrm{H}_{2} \mathrm{O} / \mathrm{ppmCO}_{2} \\
& -9.4 \times 10^{-6} \% \mathrm{H}_{2} \mathrm{O} / \mathrm{ppmCH}_{4}
\end{aligned}
$$

Although these measurements were performed on a single G2401 instrument, we expect all G1301, G2301 and G2401 analyser to exhibit similar behaviour. The first two biases are not insignificant relative to the GAW targets for $\mathrm{CO}_{2}$ and $\mathrm{CH}_{4}$ dry mole fractions. However, it is important to remember that all of these biases are included in the measurement of the water vapour correction factors at whatever mole fraction of $\mathrm{CO}_{2}$ and $\mathrm{CH}_{4}$ is used for determining the correction factors. These biases only emerge when the ambient air differs from the nominal test concentrations for $\mathrm{CO}_{2}$ and $\mathrm{CH}_{4}$. The biases are proportional to the difference between ambient and tested values, divided by the tested value, due to the fact that these offset errors are taken up by the linear coefficients during fitting of the data. For example, when the ambient dry mole fraction is $400 \mathrm{ppm}$ and the instrument is tested at $440 \mathrm{ppm}$, the $\mathrm{CO}_{2}$ error from water vapour of $0.0339 \mathrm{ppm} / \%$ water corresponds to a bias of $(440-400) / 400 \times 0.0339=$ $0.00339 \mathrm{ppm} / \% \mathrm{H}_{2} \mathrm{O}$. This bias is negligible. Similarly, for ambient methane at $2.1 \mathrm{ppm}$ measured on an instrument that was tested at $1.9 \mathrm{ppm}$, the bias in the corrected dry mole fraction is $(2.1-1.9) / 1.9 \times 1.017=0.11 \mathrm{ppb} / \% \mathrm{H}_{2} \mathrm{O}$, which is similarly negligible. Nevertheless, to avoid any unnecessary bias in the correction function, experiments deriving the correction coefficients should be performed using working standards with mole fraction close to ambient values. Finally, the bias term for water, for a $40 \mathrm{ppm}$ change in $\mathrm{CO}_{2}$ and a $0.2 \mathrm{ppm}$ change in $\mathrm{CH}_{4}$, leads to a $0.00036 \%$ bias in the water vapour concentration, which corresponds to a $0.002 \mathrm{ppm}$ bias in the reported dry mole fraction of $\mathrm{CO}_{2}$, and a $0.007 \mathrm{ppb}$ bias in the dry mole fraction of $\mathrm{CH}_{4}$. On the whole, these biases are small and can be ignored for most monitoring situations, but for best results, one may consider removing these dependencies from the reported humid values prior to testing for, and applying, the water vapour corrections.

\subsubsection{Stable isotope effects}

There is no bias in the water vapour correction factor associated with the stable isotopes of the analyte species $\mathrm{CO}_{2}$ or $\mathrm{CH}_{4}$ (although there are biases associated with the isotopic composition of the calibration tanks which must be considered, e.g., Chen et al., 2010; Nara et al., 2012). However, the stable isotope composition of water vapour must also be considered. The water vapour concentration is measured using the most abundant isotopologue of water. Variability in the other, less abundant isotopologues in the ambient air (or 
during testing for the water vapour coefficients) can lead to errors in the dry-mole fraction corrections.

The four most abundant isotopologues of water are ${ }^{1} \mathrm{H}_{2}{ }^{16} \mathrm{O},{ }^{1} \mathrm{H}_{2}{ }^{18} \mathrm{O},{ }^{1} \mathrm{H}_{2}{ }^{17} \mathrm{O}$ and ${ }^{2} \mathrm{H}^{1} \mathrm{H}^{16} \mathrm{O}$. The nominal abundances of these species are $99.7 \%, 0.21 \%, 0.038 \%$ and $0.023 \%$, respectively, with the next most abundant isotopologue having a relative abundance of just $2.4 \times 10^{-7}$. As long as these ratios remain constant throughout the process of determining the correction factors and for all ambient measurements, then there is no effect whatsoever upon the dry mole calculation. However, in the real world, the isotope ratios of water vapour can vary over a wide range: the abundances of ${ }^{1} \mathrm{H}_{2}{ }^{18} \mathrm{O},{ }^{1} \mathrm{H}_{2}{ }^{17} \mathrm{O}$, and ${ }^{2} \mathrm{H}^{1} \mathrm{H}^{16} \mathrm{O}$ relative to ${ }^{1} \mathrm{H}_{2}{ }^{16} \mathrm{O}$ can vary by up to $3 \%, 1.5 \%$ and $25 \%$, respectively, depending on the conditions under which the measurements are made (Gupta et al., 2009; Galewsky et al., 2011). Larger variations can be seen, but only in alpine or arctic environments, where the water vapour concentration is extremely low (less than $0.2 \%$ ). The errors in the three isotopologues are almost always well-correlated for naturally derived waters. We may then estimate the error in the dry-mole fraction calculations by taking the maximum value of each of these ranges as the worst case scenario. The maximal error in the estimation of the total water vapour concentration of all isotopologues from the single measurement of the ${ }^{1} \mathrm{H}_{2}{ }^{16} \mathrm{O}$ line is 1 part in 8000 . If we assume that the other isotopologues have the same broadening effect on $\mathrm{CO}_{2}$ and $\mathrm{CH}_{4}$ as does the most abundant isotopologue, this error in the water vapour concentration corresponds to a bias in the $\mathrm{CO}_{2}$ dry mole fraction of $0.0006 \mathrm{ppm} / \% \mathrm{H}_{2} \mathrm{O}$, and of $0.003 \mathrm{ppb} / \% \mathrm{H}_{2} \mathrm{O}$ for $\mathrm{CH}_{4}$. These errors are negligible compared to the GAW targets for these gases.

\section{Field validation}

\subsection{MPI - validation of $\mathrm{CO}_{2} / \mathrm{CH}_{4}$ measurements during BARCA}

One CRDS analyser (G1301) was flown without drying the air and without in-flight calibrations for two weeks on a research aircraft over the Amazon rain forest during the BARCA campaign in May 2009 (Chen et al., 2010). On the same aircraft, $\mathrm{CO}_{2}$ measurements were also made by an NDIR analyser with a drying system and frequent in-flight calibrations. Besides these two continuous in-situ measurements, air samples taken in glass flasks on the aircraft were analysed for $\mathrm{CO}_{2}$ and $\mathrm{CH}_{4}$ in the laboratory. The fact that there was no significant trend in the per flight mean differences between the two in-situ continuous $\mathrm{CO}_{2}$ measurements suggests that the $\mathrm{CO}_{2}$ measurements of the CRDS analyser (including the wet-dry corrections) were stable over the period of two weeks.

We have also compared the in-situ measurements of $\mathrm{CO}_{2}$ and $\mathrm{CH}_{4}$ from the CRDS analyser with the analysis results
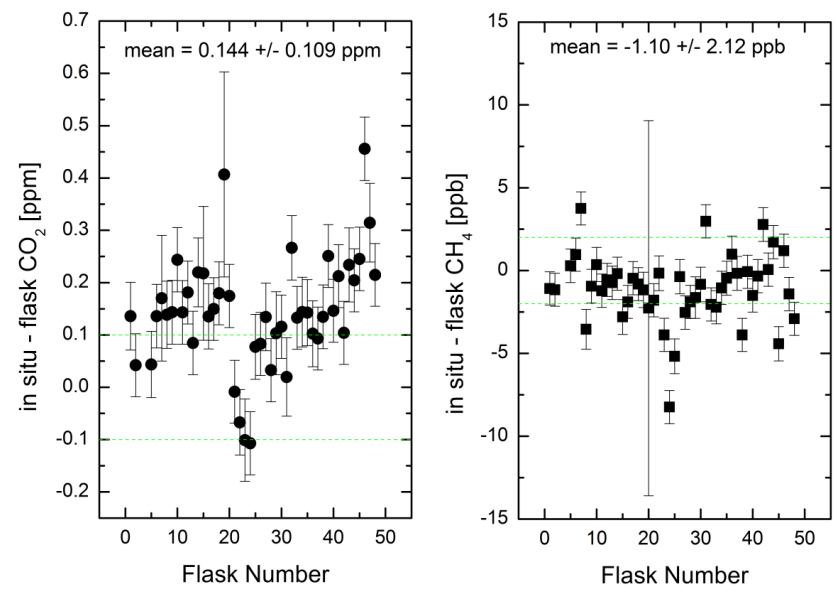

Fig. 15. Comparison between in-situ measurements and simultaneous flask measurements of $\mathrm{CO}_{2}$ (left panel) and $\mathrm{CH}_{4}$ (right panel) mole fractions, plotted as a function of flask number, with mean and standard deviations shown in each figure. The error bars are calculated based on the uncertainty of flask analyses and variability of integrated in-situ measurements with weighting functions shifted $\pm 4 \mathrm{~s}$. WMO/GAW goals are indicated by the green dashed lines in both panels.

of BARCA flask samples (see Fig. 15). For the comparison of in-situ with independent flask measurements, weighting functions have been used to integrate the in-situ measurements to account for atmospheric variability (Chen et al., 2010). Note that the uncertainty of on-site calibrations before and after the flights of the in-situ CRDS $\mathrm{CO}_{2}$ measurements was $0.14 \mathrm{ppm}$ due to needed corrections of synthetic air standards from the Harvard group (Chen et al., 2010), whereas the flask $\mathrm{CO}_{2}$ measurements were calibrated to the MPI-BGC scale with an uncertainty of $0.06 \mathrm{ppm}$. The in-situ CRDS $\mathrm{CH}_{4}$ measurements were only calibrated using MPI-BGC standards before the BARCA campaign and, therefore, both in-situ and flask $\mathrm{CH}_{4}$ measurements are on the same calibration scale with an uncertainty of $2 \mathrm{ppb}$. The MPI-BGC $\mathrm{CO}_{2}$ and $\mathrm{CH}_{4}$ scales are traceable to the WMO scales maintained in NOAA/ESRL (Dlugokencky et al., 2005; Zhao and Tans, 2006). The biases between the insitu and flask $\mathrm{CO}_{2}$ and $\mathrm{CH}_{4}$ measurements are within their measurement uncertainties. The variability of the comparison results is mainly due to unaccounted atmospheric variations. The comparison results between two independent insitu measurements and between the in-situ CRDS and flask measurements indicate that the water correction functions during the BARCA campaign were sufficient for accurate $\mathrm{CO}_{2}$ and $\mathrm{CH}_{4}$ measurements.

\subsection{LSCE - parallel measurements of $\mathrm{CO}_{2}$ and $\mathrm{CH}_{4}$ at Mace Head}

Two CRDS instruments are running at the Mace Head (MHD) atmospheric monitoring station. The setup for 


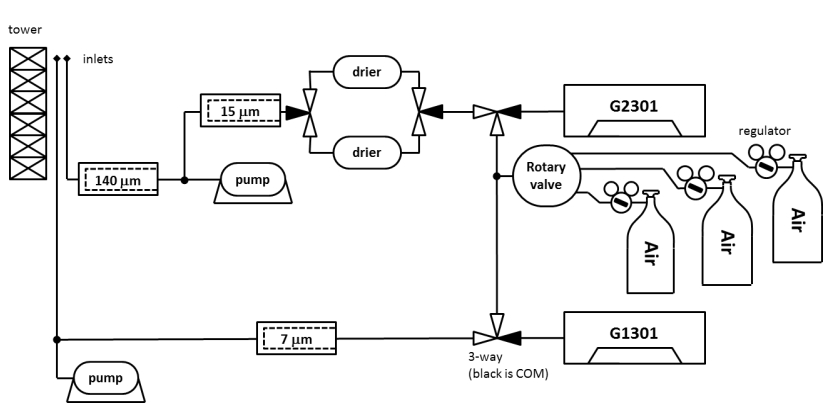

Fig. 16. Schematic for performing parallel measurements at the Mace Head (MHD) station. The tower lines were flushed at about 2-3 $\mathrm{L} \mathrm{min}^{-1}$, and the instrument flows were $110 \mathrm{~mL} \mathrm{~min}^{-1}$ for the G1301 and $200 \mathrm{~mL} \mathrm{~min}^{-1}$ for the G2301.

performing the parallel measurements is shown in Fig. 16. One instrument is a G1301 (CFADS046) that belongs to the Irish EPA. This instrument has been running at the station since May 2009 measuring ambient air without drying. The second instrument is a G2301 (CFADS2122) owned by LSCE, and which was co-located at MHD in March of 2011. This instrument measures ambient air after a cryogenic water trap. Each of the two instruments is equipped with a dedicated ambient air line (1/2" O.D. Synflex) leading to an inlet at the top of a $20 \mathrm{~m}$ high mast. Both instruments share the same multi-position valve (VICI EMT2CSD8UWE), which means that they use the same calibration and target tank, as well as the same measurement sequence (i.e., ambient measurements and calibration are performed at the same time). Both instruments use the same water vapour correction coefficients as described in Chen et al. (2010).

Measurements were made over a period of about 2 months in this configuration, during which time the ambient water vapour concentration varied over a range from $0.8-1.8 \%$. The measurement results are shown in Fig. 17. The top graph of each panel $\left(\mathrm{CO}_{2}\right.$ on the left, $\mathrm{CH}_{4}$ on the right) shows the two datasets, along with the difference between the two instruments. There is a fair amount of scatter in the difference. In the bottom graphs of each panel, the results for the dry target tanks are also shown, along with the difference between the two instruments. Clearly the G2301 has a much higher degree of drift than the G1301. This drift is in fact mirrored in the ambient air differences, with a high degree of correlation (note: as a result of these observations, the G2301 was shipped back to the manufacturer for repair, where this fault was corrected). We highlight the fact that the instrument noise, averaged on a time period of $30 \mathrm{~s}$ or greater, is generally $0.04 \mathrm{ppm}$ or less for $\mathrm{CO}_{2}$ and $0.5 \mathrm{ppb}$ or less for $\mathrm{CH}_{4}$; this noise is not significant on the scale of the WMO/GAW targets. The drift in this instrument tends to mask the performance of the water correction methodology. For this reason, the target tank data was used as a single-point calibration to better track and correct for this drift. The result of this drift correction process is shown in Fig. 18, show- ing the hourly difference between the two instruments over time, as well as a histogram of this difference. Finally, in Fig. 19, the dependence of the difference is plotted against water vapour and the analyte gases. Both the bias and the standard deviation are well within the compatibility targets for both gases, indicating that the water vapour correction of the G1301 is not biasing or otherwise degrading the results up to about $1.8 \% \mathrm{H}_{2} \mathrm{O}$.

\subsection{Empa and FMI - parallel measurements of $\mathrm{CO}_{2}$ and $\mathrm{CH}_{4}$ at Pallas}

Parallel measurements using two G2401 CO, $\mathrm{CO}_{2}, \mathrm{CH}_{4}$ and $\mathrm{H}_{2} \mathrm{O}$ analysers were made at the Global GAW station Pallas $\left(67.97^{\circ} \mathrm{N}, 24.12^{\circ} \mathrm{E}, 560 \mathrm{~m}\right.$ a.s.1.) as part of a system and performance audit conducted by the World Calibration Centre WCC-Empa within the framework of the WMO/GAW quality assurance system.

The Pallas G2401 (CFKADS-2018) instrument is connected to the common air inlet system of the station. The inlet system consists of an acid-proof stainless steel manifold with an outer diameter of $60 \mathrm{~mm}$, and it is continuously flushed with a nominal flow rate of $130 \mathrm{~m}^{3} \mathrm{~h}^{-1}$ (residence time $1 \mathrm{~s}$ ). From there the analyser is connected by $1 / 8 \mathrm{inch}$ stainless steel (SS) tubing. The sample air passes through a 3-way solenoid valve to a Nafion dryer (Perma Pure MD070-96S-2) and then to the analyser. Purge air for the Nafion is taken from the analyser's vacuum line (reflux method). The Nafion was operated at about $20^{\circ} \mathrm{C}$, with the sample side at a slight underpressure relative to atmospheric pressure (about -0.02 bar), and the purge side at about 0.1 bar absolute. A target cylinder of dried compressed air is connected to the remaining port of the 3-way valve. The target cylinder is measured every $9.5 \mathrm{~h}$ for $15 \mathrm{~min}$. This Nafion based drying system achieves a water vapour mole fraction of approximately $0.1 \%$ (range $0.04-0.15 \%$ ) for the sample air. It also humidifies the air from the target cylinder to about the same water content. The analyser uses the coefficients in Chen et al. (2010) to correct for residual water concentration. The analyser is calibrated against a set of WMO/CCL standards $4-5$ times a year, at which time each cylinder is measured for $30 \mathrm{~min}$. The target cylinder results are not used to adjust the data between calibrations.

For the WCC-Empa G2401 (CFKADS-2001), two separate inlet lines are used. The measurement cycle is as follows: the air is sampled for $30 \mathrm{~h}$ from a separate $1 / 4 \mathrm{inch}$ Synflex tubing which is additionally flushed by a by-pass pump at $2 \mathrm{~L} \mathrm{~min}^{-1}$. The air intake of the separate inlet line is mounted within $0.5 \mathrm{~m}$ from the Pallas inlet. Afterwards, the air is sampled for $10 \mathrm{~h}$ from the Pallas manifold. Then, 3 standards (one working and two target tanks) are measured for $15 \mathrm{~min}$ each. This sequence is repeated throughout the whole measurement campaign. The sample air is not dried in contrast to the Pallas instrument, and a correction which was determined by Method \#2 is applied to the data. For 

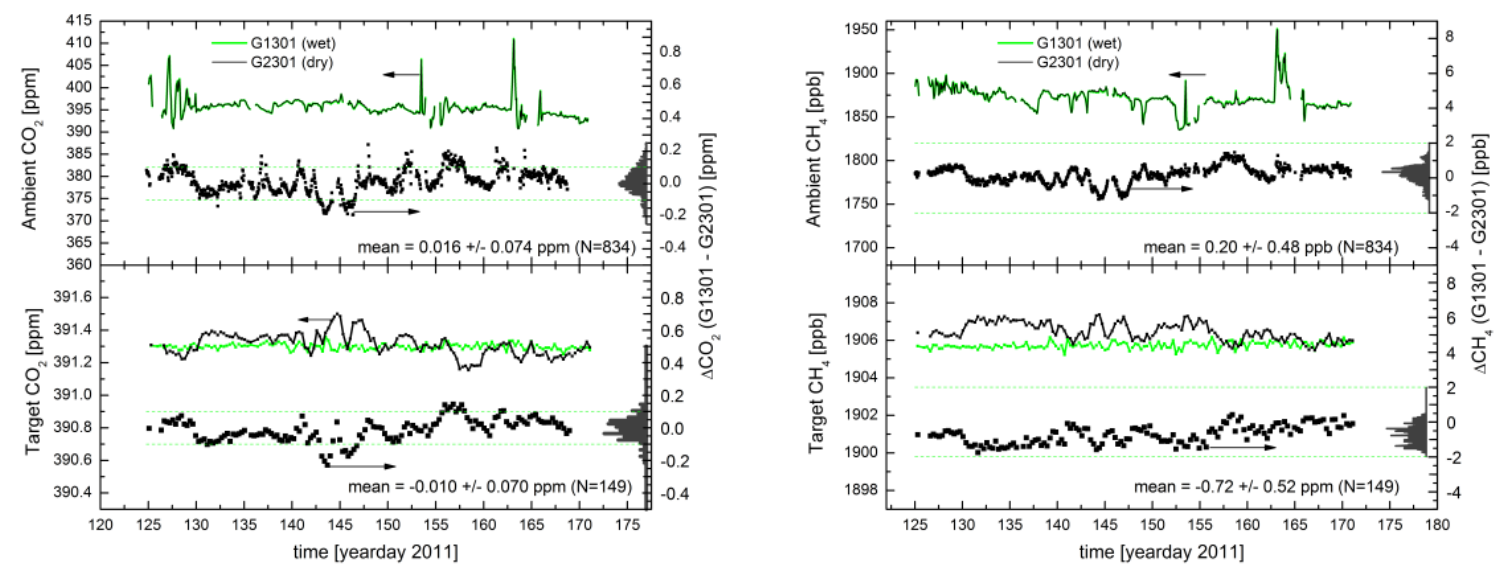

Fig. 17. Comparison between G1301 (wet) and G2301(dry) at $\mathrm{MHD}$ for $\mathrm{CO}_{2}$ (left panels) and $\mathrm{CH}_{4}$ (right panels). The top panel for each species shows the hourly data for both instruments (green and blue curves, left axes) as well as the difference (black points, right axes). The bottom panels indicate the results for the target tank measurements for each instrument (green and black curves, left axes), as well as the difference (black points, right axis). The right-hand axis of each panel also shows a histogram of the differences, and the mean and standard deviations for these distributions are noted in each panel. The green dashed lines indicate the WMO/GAW targets for each gas. Note, the dramatically higher drift in the G2301 target tank, which is mirrored in the difference between the two instruments for both the target tank and ambient measurements. This drift is due to a failure of the G2301 instrument (see text).

the G2401 CFKADS-2001, the following fitting parameters were derived:

$$
\begin{aligned}
\mathrm{CO}_{2}: a & =-1.186 \times 10^{-2} \pm 1.029 \times 10^{-5}, \\
b & =-2.497 \times 10^{-4} \pm 3.446 \times 10^{-6} \\
\mathrm{CH}_{4}: a & =-9.635 \times 10^{-3} \pm 1.818 \times 10^{-5}, \\
b & =-1.917 \times 10^{-4} \pm 6.091 \times 10^{-6}
\end{aligned}
$$

The dry air mole fraction calculated based on this method was then corrected for instrument drift using the working standard measurements that were made every $40 \mathrm{~h}$. Figure 20 shows the 1-min time series for $\mathrm{CO}_{2}$ (upper left panel) and $\mathrm{CH}_{4}$ (upper right panel) measured with the Pallas and the WCC G2401 instruments for the period from 20th April to 30 May 2012. The WCC analyser was using its own inlet system (black) alternating with the manifold of the Pallas station (red). The water vapour is also plotted in the upper panels. The difference between the Pallas and the WCC instruments is plotted in the lower panels of Fig. 20, along with a histogram of the difference. Both instruments capture changes in the $\mathrm{CO}_{2}$ and $\mathrm{CH}_{4}$ mole fractions very well. It can also be seen that the two independent inlet systems gave identical results with no significant change in the $\mathrm{CO}_{2}$ or $\mathrm{CH}_{4}$ mole fraction for both inlets. Furthermore, the bias between the two instruments did not depend strongly on the water vapour content of the ambient air or on the analyte gases themselves, which is illustrated in Fig. 21. This lack of dependence of the bias on water vapour indicates that the applied correction function as determined by the experiment in Sect. 3.1.2 is fully adequate to compensate for $\mathrm{H}_{2} \mathrm{O}$ dilution and interference.
Figure 22 shows the water mole fraction measured with the Pallas G2401 analyser after the Nafion dryer (right yaxis) and the ambient $\mathrm{H}_{2} \mathrm{O}$ (left y-axis). The ambient $\mathrm{H}_{2} \mathrm{O}$ levels ranged from 0.24 to $1.27 \%$; after drying, the remaining humidity ranged from 0.05 to $0.11 \%$. However, it should be noted that the $\mathrm{H}_{2} \mathrm{O}$ mole fraction after the Nafion dryer regularly dropped by approx. $0.005 \%$ when the Pallas working standard was measured. This effect is caused by humidification by the Nafion dryer of the working standard, which itself is completely dry. For $\mathrm{CO}_{2}$, this can result in a bias of approx. $0.02 \mathrm{ppm}$ at ambient mole fractions of $400 \mathrm{ppm} \mathrm{CO}_{2}$.

\subsection{Penn State University - parallel measurements of $\mathrm{CO}_{2}$ in Indianapolis}

To assess the accuracy of the water vapour correction in field conditions, two CRDS instruments (Picarro, Inc., Santa Clara, CA, USA, models CADS and G2401) were co-located at a tower in Indianapolis, IN for 3 months. 1/4" O.D. Synflex tubing (part number 1300-04403) was used from the sample level (121 m above ground level) to the instruments, with a 3-way compression fitting to split the flow. While the G2401 instrument was sampling gas dried using a Nafion dryer (Permapure, part number MD-110-24S-2), with a dry air generator (Twin Tower Engineering, part number MW200) providing the counter flow, the CADS instrument was sampling humid air and relied on the internal water vapour correction. The CADS instrument is different from the other instruments in this study, in the sense that the water vapour is measured using a different spectroscopic line than the other instrumentation, due to the fact that the laser used to measure the water vapour in the G1301 and G2301 is not available in 

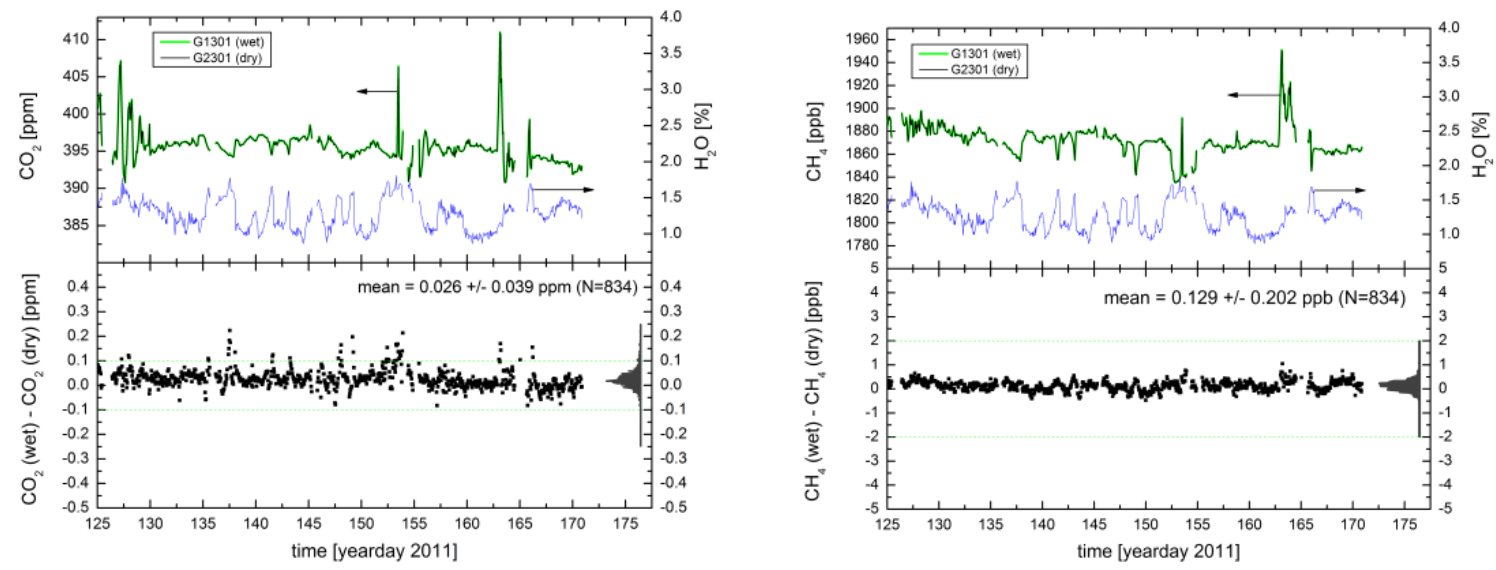

Fig. 18. Comparison between $\mathrm{G} 1301$ (wet) and $\mathrm{G} 2301$ (dry) at $\mathrm{MHD}$ for $\mathrm{CO}_{2}$ (left panels) and $\mathrm{CH}_{4}$ (right panels), using the target tank as a single point calibration for the G2301 only. Top panels: the hourly data for both instruments (green and black curves, left axes). The water signal from the G1301 is shown on the right hand axis of the upper panel. The lower panels show the difference between the two instruments, along with a histogram of the target-corrected difference between the G1301 (wet) and G2301 (dry) measurements. The WMO/GAW goals for each gas are indicated by the green dashed lines.
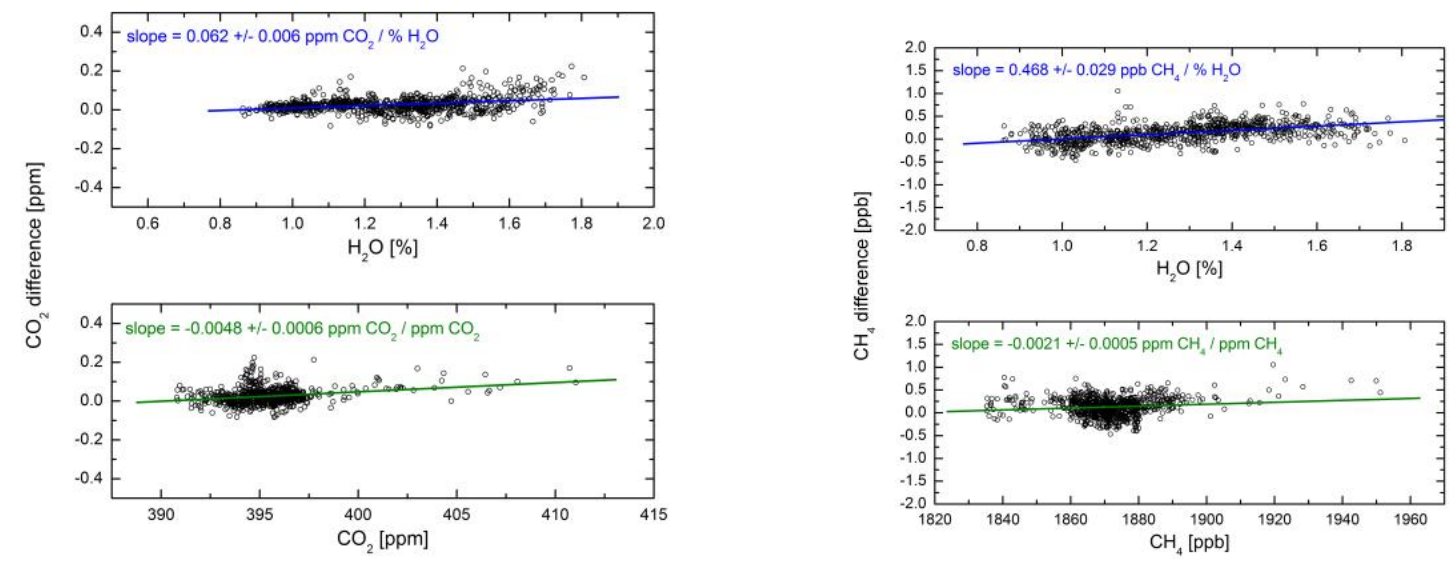

Fig. 19. Dependence of the difference between the two instruments against $\mathrm{H}_{2} \mathrm{O}$ and the analyte gas, for $\mathrm{CO}_{2}$ (left panels) and $\mathrm{CH}_{4}$ (right panels).

the CADS instrument (Richardson et al., 2012). To crosscalibrate the two spectroscopic lines, a special test was performed on a G1301 that was modified to measure both lines quasi-simultaneously (alternating between the two measurements every three seconds), while ramping the water vapour concentration over a substantial range $(0-3 \%)$. The software of the CADS instrument was then modified so that the water vapour concentration was reported on the same scale as the G1301. The wet-dry coefficients used were those described in Chen et al. (2010).

Figure 23 shows a schematic of the sampling and measurement components of the two systems. Both systems used Parker Inc. (Cleveland, OH, USA, part number 003-0216900) valves, Air Liquide (Plumsteadville, PA, Model 5114B-590) regulators and $1 / 8^{\prime \prime}$ O.D. stainless steel tubing. Field calibrations were performed separately for each sys- tem, sampling NOAA-ESRL tanks for $10 \mathrm{~min}$ each every $23 \mathrm{~h}$. The $\mathrm{CO}_{2}$ only field standards for the CADS system were prepared by NOAA-ESRL (thus containing near atmospheric values of $\mathrm{CO}_{2}$ isotopic ratios) and were calibrated at Penn State, while the field standards for the G2401 system were prepared and calibrated by NOAA-ESRL. The G2401 system also sampled an additional tank hourly to assess drifts in the $\mathrm{CO}$ measurement, and sampled $10 \mathrm{~m}$ and $40 \mathrm{~m}$ above ground level hourly as well. Data from the CADS system were subsampled according to when the G2401 data were available and hourly values were compared. Water vapour values ranged from $0.5 \%$ to higher than $4 \%$. While these high levels give some reason to suspect that the inlet line upstream of both analysers may have been contaminated with liquid water during the measurements, the fact that both instruments are sampling from the same inlet means that this 

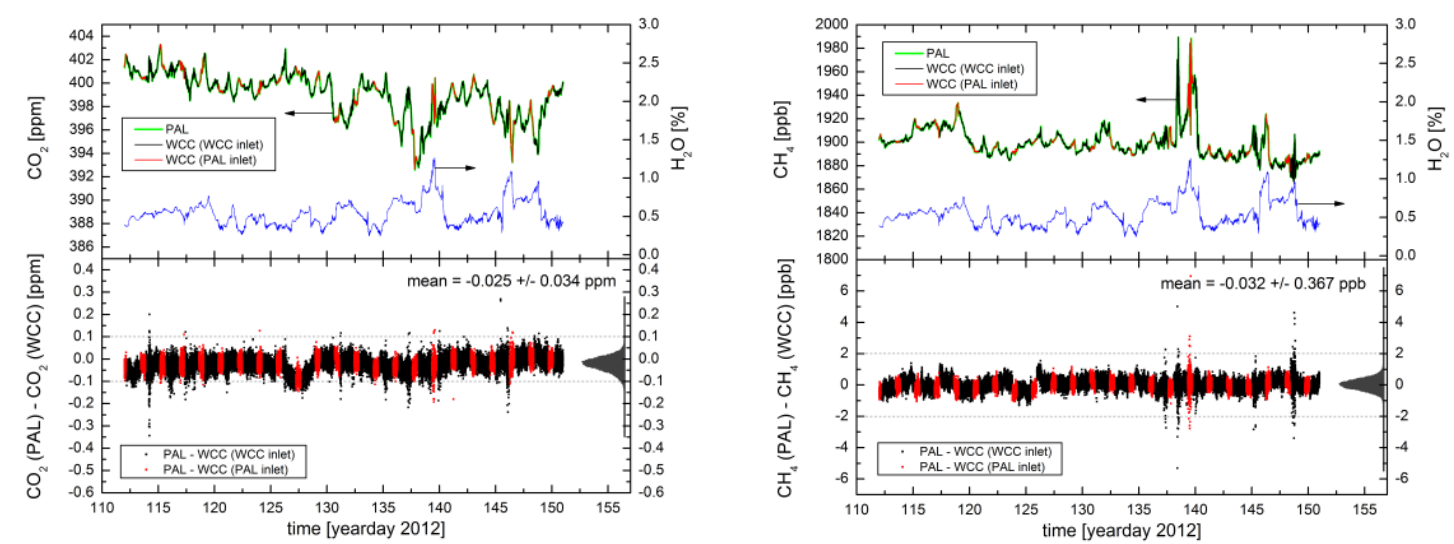

Fig. 20. Upper panels: 1-min average $\mathrm{CO}_{2}$ (left panels) and $\mathrm{CH}_{4}$ (right panels) mole fractions measured at Pallas by the Pallas G2401 with sample drying and the WCC G2401 without sample drying. The WCC instrument was alternating between its own inlet system and the Pallas manifold. The right axes of the upper panels show $\mathrm{H}_{2} \mathrm{O}$ as measured by the WCC instrument. Lower panels: difference between the two analysers, along with a histogram of the difference; the mean and standard deviation of the distributions are noted in the lower panels. Dashed lines correspond to WMO/GAW targets.
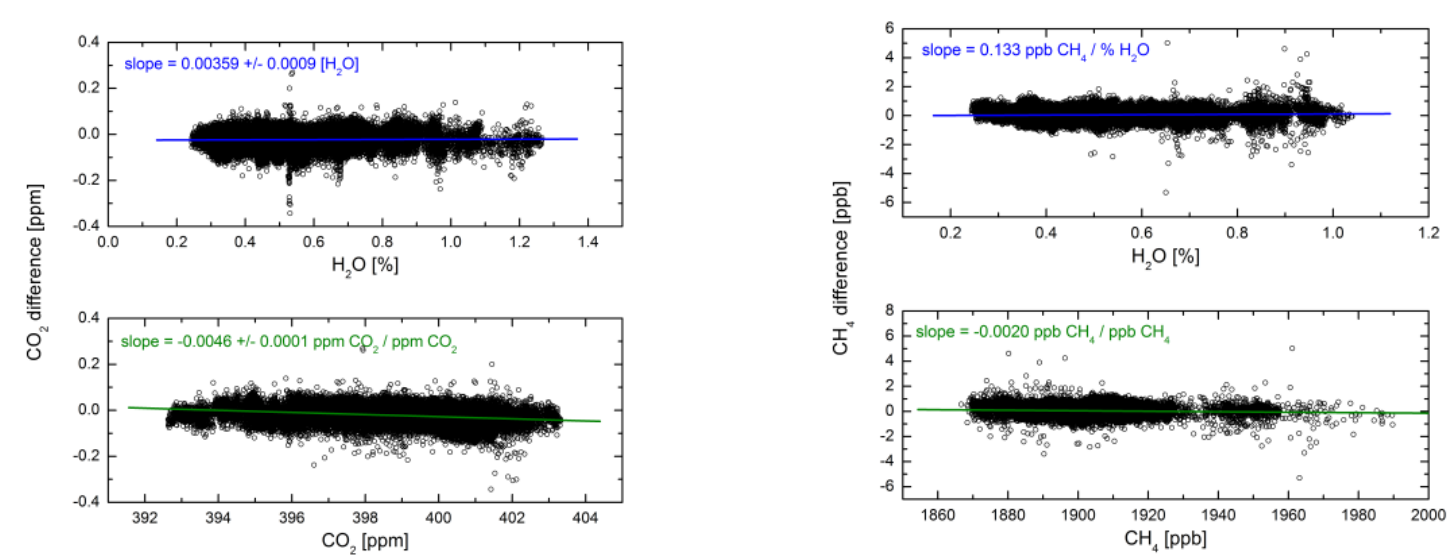

Fig. 21. Dependence of the difference between the two instruments against $\mathrm{H}_{2} \mathrm{O}$ and the analyte gas, for $\mathrm{CO}_{2}\left(\right.$ left panels) and $\mathrm{CH}_{4}$ (right panels).

potential contamination would not affect the head-to-head comparison presented here.

Figure 24 shows the difference between the $\mathrm{CO}_{2}$ levels of the two systems (top panel), along with the water vapour signal during that time period. The bottom panel of this figure shows the measured difference between the two instruments, along with a histogram of the difference. Eight hourly data points were removed from the dataset because the absolute value of the difference between the two instruments was greater than $0.5 \mathrm{ppm}$. Mean and standard deviation of the difference was $0.01 \pm 0.09$ ppm over a period of 90 days. In Fig. 25, the difference is plotted against $\mathrm{H}_{2} \mathrm{O}$ (top panel) and $\mathrm{CO}_{2}$ (bottom panel) least squares best fit line to the $\mathrm{CO}_{2}$ difference as a function of water vapour indicated a quadratic water vapour dependence, with a range of $\pm 0.085 \mathrm{ppm} \mathrm{CO}_{2}$ for $\mathrm{H}_{2} \mathrm{O}$ over $0-5 \%$. This residual error is due to the uncertainty involved with using the Chen et al. (2010) coeffi- cients, as described in Section 4.4, and is compounded by the fact that the water level rose to such high levels. The difference in $\mathrm{CO}_{2}$ also had a $\mathrm{CO}_{2}$ dependence, decreasing from $0.07 \mathrm{ppm}$ at $360 \mathrm{ppm}$ to $-0.05 \mathrm{ppm}$ at $420 \mathrm{ppm}$, indicating an issue with the calibration between the two instruments. Both of these dependencies lead to biases that are smaller than the WMO inter-laboratory compatibility goal of $\pm 0.1 \mathrm{ppm}$ for $\mathrm{CO}_{2}$.

\subsection{NOAA - parallel measurements of $\mathrm{CO}_{2}$ at the $\mathrm{BAO}$ tall tower}

The CRDS instrument (Model G1301, SN CFADS09) was installed for about two months during Fall 2011 at the 300$\mathrm{m}$ tall Boulder Atmospheric Observatory (BAO) tower near Boulder, $\mathrm{CO}$, where routine in-situ measurements are made using a LI-COR NDIR $\mathrm{CO}_{2}$ analyser on a dried ambient air stream (Andrews et al., 2013). The water vapour correction 


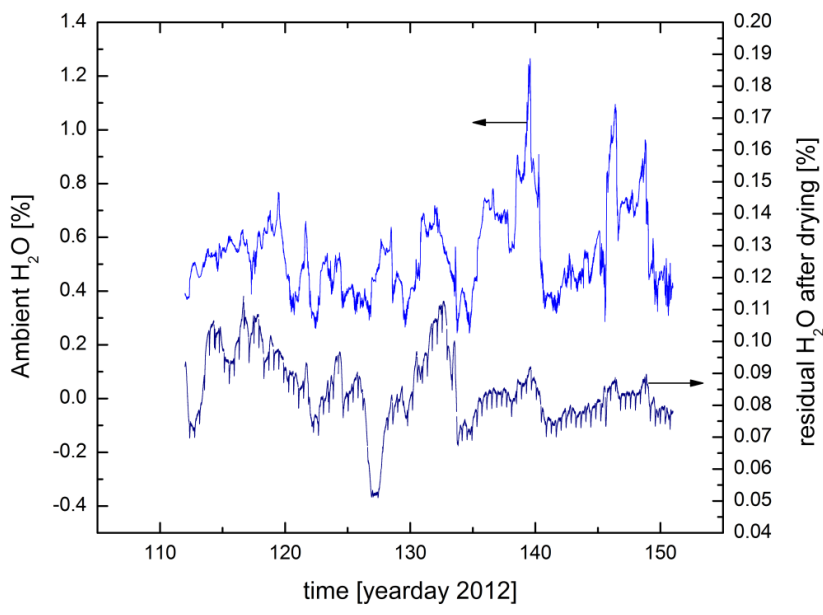

Fig. 22. $\mathrm{H}_{2} \mathrm{O}$ mole fractions measured with the Pallas instrument after the Nafion dryer (right axis, dark blue line) and ambient $\mathrm{H}_{2} \mathrm{O}$ measured with the WCC instrument (left axis, light blue line).

coefficients were measured in the laboratory using Method \#2 several months prior to this deployment. Ambient air for the CRDS instrument was drawn from a dedicated inlet line directly into the instrument. The sample airstream for the NDIR LI-COR instrument (model Li-7000) was drawn from a separate inlet line and compressed to approximately 10 p.s.i.g, passed through a chilled glass trap $\left(1.5^{\circ} \mathrm{C}\right)$, a solenoid manifold, and a $144^{\prime \prime}$ Nafion membrane dryer. The LI-COR baseline drift is monitored every $2 \mathrm{~h}$, and a full calibration is performed twice per day. The flow rates through the two inlet systems were nearly the same, and a constant time offset was applied to account for different lag times through the $300 \mathrm{~m}$ long inlet line.

The top panel of Fig. 26 shows the $\mathrm{CO}_{2}$ time series for a typical 3 day period from both instruments. When the CRDS data stream is averaged over $30 \mathrm{~s}$, the results become essentially indistinguishable on this graph. The $\mathrm{H}_{2} \mathrm{O}$ signal for the same time period is shown in the right hand axes of the top panel. The bottom panel of Fig. 26 shows the difference between the two sets of measurements, along with a histogram of the difference. Seven data points (about $0.1 \%$ of the total) were removed from the plot because the difference between the two instruments was larger than $0.5 \mathrm{ppm}$. The mean difference between the two measurements over this period of time is $0.044 \mathrm{ppm}$, with a standard deviation of $0.053 \mathrm{ppm}$, well within the stated GAW compatibility goal of $0.1 \mathrm{ppm}$. This observation provides further strong evidence that the dry-mole fraction reported by the G1301 on humid air is statistically indistinguishable from measurements made on the dried sample gas using NDIR technology. Finally, in Fig. 27, the difference between the two measurements is plotted vs. water vapour (top panel) and carbon dioxide (bottom panel). No significant bias is visible with respect to water vapour, although there is a small bias with respect to $\mathrm{CO}_{2}$. The G1301 used in this study was not carefully calibrated,

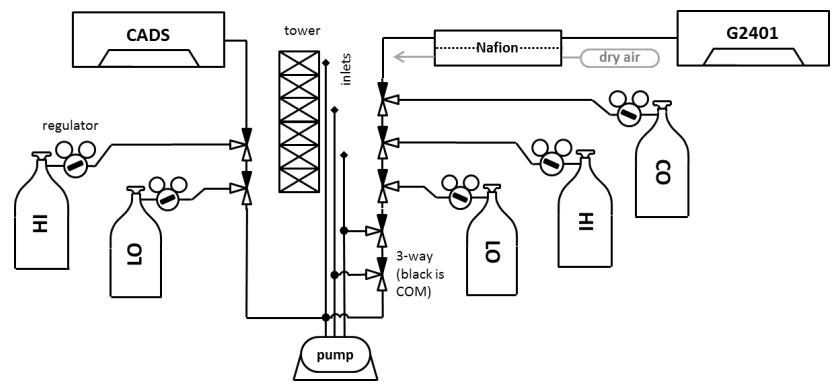

Fig. 23. Setup for parallel measurements in Indianapolis by Penn State University.

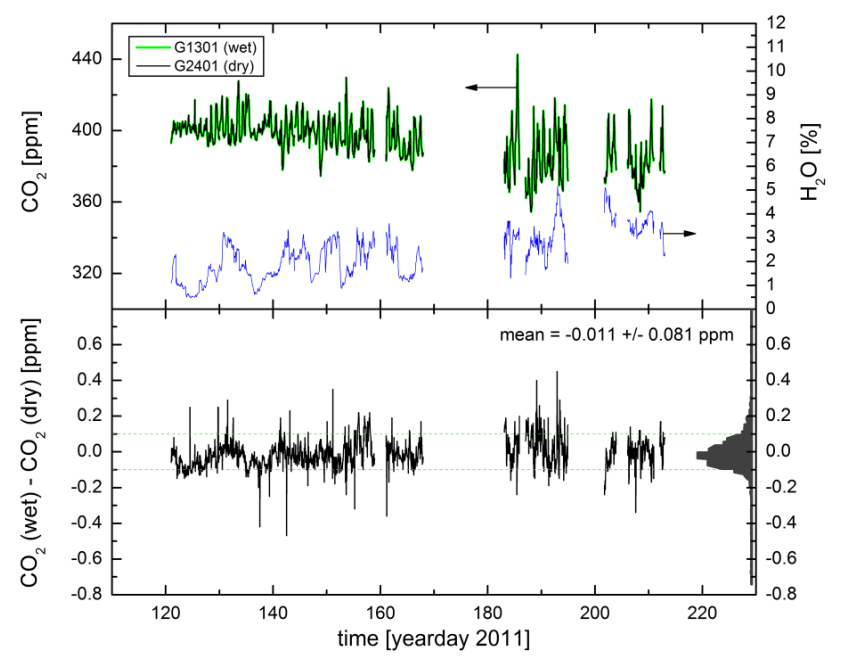

Fig. 24. Difference in $\mathrm{CO}_{2}$ as measured between two CRDS systems in Indianapolis measuring atmospheric air from a height of $121 \mathrm{~m}$ above ground level, one with drying and one without, averaged on an hourly basis. Upper panel: $\mathrm{CO}_{2}$ mole fraction by the G1301 (wet) and the G2401 (dry). The right axis of the upper panel shows $\mathrm{H}_{2} \mathrm{O}$ as measured by the G1301. Lower panels: difference between the two analysers, along with a histogram of the difference; the mean and standard deviation of the distributions are noted in the lower panels. Dashed lines correspond to WMO/GAW targets.

so the small observed slope is not surprising. During this test the water vapour level varied from about 0.6 to $1.4 \%$ as measured by the G1301.

\section{Conclusions}

Until recently, it has been accepted in the world of greenhouse gas monitoring that drying to low levels (below $-25^{\circ} \mathrm{C}$ dew point) is required for high quality measurements which meet or exceed the WMO targets for inter-laboratory compatibility. However, recent advances in laser-based optical spectroscopy have allowed high quality dry mole fraction measurements of $\mathrm{CO}_{2}$ and $\mathrm{CH}_{4}$ directly in the humid gas stream. Operating without drying allows one to measure the 


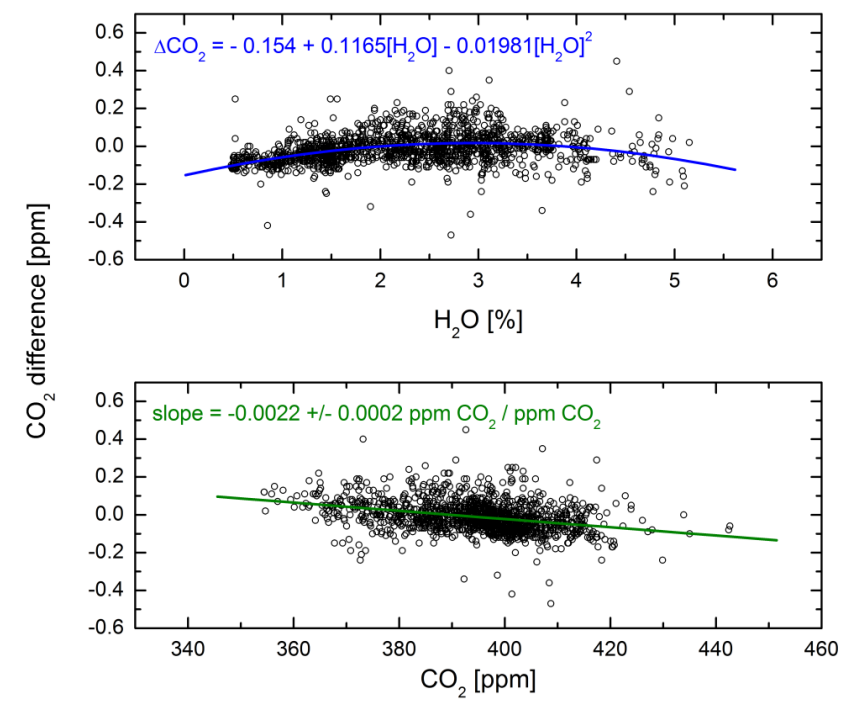

Fig. 25. Dependence of the difference between the two instruments in Indianapolis against $\mathrm{H}_{2} \mathrm{O}$ (top panel) and $\mathrm{CO}_{2}$ (bottom panel).

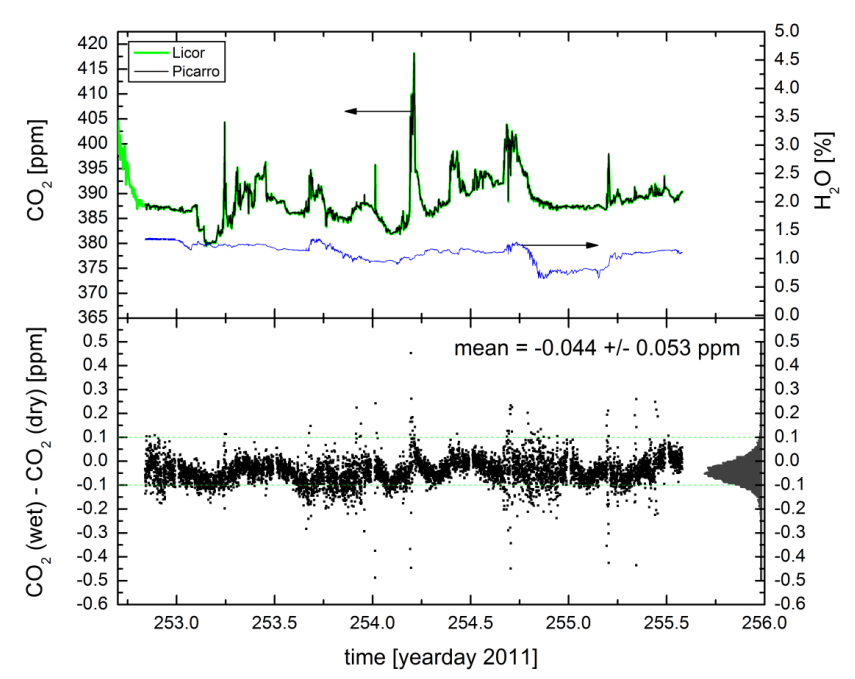

Fig. 26. $\mathrm{CO}_{2}$ as measured by a LI-COR system measuring a dry gas stream and a G2401 measuring humid ambient air at BAO tower near Boulder, Colorado. Both instruments are averaged on a 30-s window. Upper panel: $\mathrm{CO}_{2}$ mole fraction by the LI-COR (dry) and the $\mathrm{G} 2401$ (wet). The right axis of the upper panel shows $\mathrm{H}_{2} \mathrm{O}$ as measured by the G2401. Lower panels: difference between the two analysers, along with a histogram of the difference; the mean and standard deviation of the distributions are noted in the lower panels. Dashed lines correspond to WMO/GAW targets.

ambient water vapour level, an important atmospheric tracer for air mass changes, as well as serving as a diagnostic for condensation or other liquid contamination in the inlet system. Several leading research laboratories have demonstrated the performance of these CRDS analysers both in the lab and in the field. Some of these key results are collected here. From these results, we may draw the following conclusions:

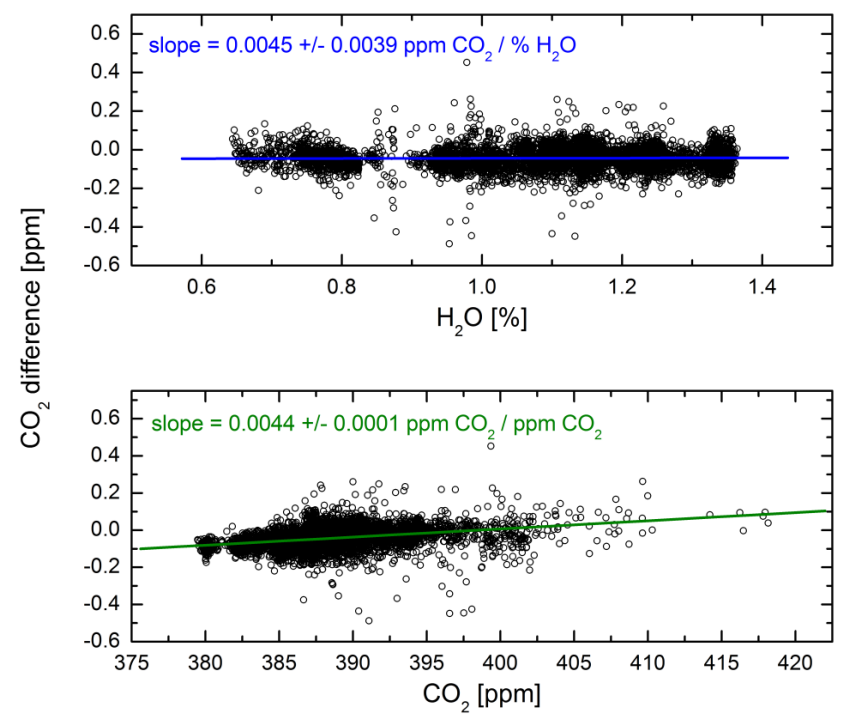

Fig. 27. Dependence of the difference between the two instruments at $\mathrm{BAO}$ against $\mathrm{H}_{2} \mathrm{O}$ (top panel) and $\mathrm{CO}_{2}$ (bottom panel).

1. There are at least two straightforward and effective methods for determining the water vapour correction factors (with several variations). Measurements on multiple instruments, and on a single instrument over time, indicate that the analysers exhibit the high degree of stability necessary to maintain high standards for accuracy over time. The methods for performing this test are straightforward and do not require cumbersome or highly specialised equipment, and can be performed in the laboratory or even in the field, provided that some care is taken to remove potential biases in the measurement due to dissolved $\mathrm{CO}_{2}$ and $\mathrm{CH}_{4}$ in the liquid water. No significant biases have been detected between the different methods, or between the different implementations performed at different laboratories.

2. By using the single set of values for the water vapour correction factors described in Chen et al. (2010), it is possible to make measurements of $\mathrm{CO}_{2}$ and $\mathrm{CH}_{4}$ that meet the GAW inter-laboratory compatibility targets (in the Northern Hemisphere) for water vapour concentrations up to at least $1 \%$ and perhaps up to $2 \%$, limited primarily by the $\mathrm{CO}_{2}$ uncertainty. $1 \% \mathrm{H}_{2} \mathrm{O}$ corresponds to a dew point of about $5^{\circ} \mathrm{C}$. In the Southern Hemisphere, this limit drops to about $0.6 \% \mathrm{H}_{2} \mathrm{O}$. This result is already a significant step forward, allowing the use of simpler, less effective drying techniques (0.1-0.3\% residual water vapour) than those typically employed in the atmospheric greenhouse gas monitoring community $(<0.005 \%$ residual water vapour). In particular, this strategy has been adopted by Earth Networks, a commercial greenhouse gas monitoring network (Welp et al., 2012), and has been recommended elsewhere (Nara 
et al., 2012). Also, it is important to note that many alpine or other cold weather locales never experience humidity levels above $1 \%$.

3. By measuring the water vapour correction factors at the start of life on a per-instrument basis as described in Sect. 3, the range of water vapour mole fraction can be extended up to at least $2 \%$ and perhaps up to $2.5 \%$, again limited by the $\mathrm{CO}_{2}$ requirement in the Northern Hemisphere. In addition, the uncertainty over most of the water vapour range below these limits is reduced dramatically from the situation when using a single set of coefficients. In the Southern Hemisphere, the narrower target for $\mathrm{CO}_{2}$ means that the uncertainty of the correction is of the order of $\pm 0.05 \mathrm{ppm}$, up to about $2.2 \%$ water vapour.

4. By carefully measuring the water vapour correction factors periodically, the evidence suggests that the range of water vapour over which GAW quality measurements can be made extends above $4 \%$, covering even the most humid ambient conditions.

5. Several in-situ comparison studies between measurements on humid and dry ambient gas streams have been performed to date, using water vapour correction coefficients determined using the methods described in this manuscript. In these studies, the mean difference between wet and dry measurements is observed to be within GAW compatibility targets for the ranges of water vapour experienced (typically up to about $1-1.5 \%$ ), indicating that the laboratory methodologies for determining these coefficients generate unbiased results. In addition, the standard deviation of the difference between the dry mole fractions measured in humid and dry measurements is also well within GAW targets. This result is an important validation of the idea that simply by measuring the water vapour concentration of ambient air in a highly precise and stable (though not necessarily accurate) way, the dry-mole fraction can be determined with a high degree of precision and accuracy (provided standards are applied in an appropriate manner).

Given conclusion \#4, above, it would be desirable to devise a method for quantifying the water vapour correction factors in situ in an automated fashion. Such a method would further simplify the field deployment of these analysers and improve the quality of the data, by increasing the frequency of the determination of the water correction coefficients. We emphasise that a field deployable method that would meet the requirements of periodically testing the water vapour correction coefficients need not be a complete measurement method, such as those methods described in this paper. It is likely to be sufficient to periodically check the proper operation of the dry-mole fraction reporting, such as by humidifying (e.g., with Nafion) a standard or target tank.

\section{Supplementary material related to this article is available online at: http://www.atmos-meas-tech.net/6/ 837/2013/amt-6-837-2013-supplement.pdf.}

Acknowledgements. Laboratory experiments at the Max Planck Institute for Biogeochemistry were supported through the IAGOS research infrastructure, funded in its preparatory phase under the European Community's Seventh Framework Programme FP7, grant agreement no. 212128. The measurement campaign at Pallas was supported by MeteoSwiss through engagement in the WMO Global Atmosphere Watch Programme. A portion of the data from Mace Head observatory was provided thanks to Michael Geever and Gerard Spain from National University of Ireland, Galway; and thanks to David Dood from Environment Protection Agency, Dublin, Ireland. Finally, the authors would also like to thank R. Keeling, R. Weiss, and L. Welp-Smith for thoughtful discussion.

Edited by: O. Tarasova

\section{References}

Andrews, A. E., Kofler, J. D., Trudeau, M. E., Williams, J. C., Neff, D. H., Masarie, K. A., Chao, D. Y., Kitzis, D. R., Novelli, P. C., Zhao, C. L., Dlugokencky, E. J., Lang, P. M., Crotwell, M. J., Fischer, M. L., Parker, M. J., Lee, J. T., Baumann, D. D., Desai, A. R., Stanier, C. O., de Wekker, S. F. J., Wolfe, D. E., Munger, J. W., and Tans, P. P.: $\mathrm{CO}_{2}, \mathrm{CO}$ and $\mathrm{CH}_{4}$ measurements from the NOAA Earth System Research Laboratory's Tall Tower Greenhouse Gas Observing Network: instrumentation, uncertainty analysis and recommendations for future highaccuracy greenhouse gas monitoring efforts, Atmos. Meas. Tech. Discuss., 6, 1461-1553, doi:10.5194/amtd-6-1461-2013, 2013.

Bousquet, P., Peylin, P., Ciais, P., Le Quéré, C., Friedlingstein, P., and Tans, P. P.: Regional Changes in Carbon Dioxide Fluxes of Land and Oceans since 1980, Science, 290, 1342-1346, doi:10.1126/science.290.5495.1342, 2000.

Bakwin, P. S., Tans, P. P., Zhao, C., Ussler, W., and Quesnell, E.: Measurements of carbon dioxide on a very tall tower, Tellus, 47B, 535-549, 1995.

Chen, H., Winderlich, J., Gerbig, C., Hoefer, A., Rella, C. W., Crosson, E. R., Van Pelt, A. D., Steinbach, J., Kolle, O., Beck, V., Daube, B. C., Gottlieb, E. W., Chow, V. Y., Santoni, G. W., and Wofsy, S. C.: High-accuracy continuous airborne measurements of greenhouse gases $\left(\mathrm{CO}_{2}\right.$ and $\left.\mathrm{CH}_{4}\right)$ using the cavity ringdown spectroscopy (CRDS) technique, Atmos. Meas. Tech., 3, 375-386, doi:10.5194/amt-3-375-2010, 2010.

Chen, H., Winderlich, J., Gerbig, C., Katrynski, K., Jordan, A., and Heimann, M.: Validation of routine continuous airborne $\mathrm{CO}_{2}$ observations near the Bialystok Tall Tower, Atmos. Meas. Tech., 5, 873-889, doi:10.5194/amt-5-873-2012, 2012.

Corbin, K. D., Denning, A. S., Lokupitiya, E. Y., Schuh, A. E., Miles, N. L., Davis, K. J., and Richardson, S.: Assessing the impact of crops on regional $\mathrm{CO}_{2}$ fluxes and atmospheric concentrations, Tellus B, 62, 521-532, doi:10.1111/j.16000889.2010.00485.x, 2010.

Crosson, E. R.: A cavity ring-down analyser for measuring atmospheric levels of methane, carbon dioxide, and water 
vapour, Appl. Phys. B, 92, 403-408, Springer Berlin/Heidelberg, doi:10.1007/s00340-008-3135-y, 2008.

Dlugokencky, E. J., Myers, R. C., Lang, P. M., Masarie, K. A., Crotwell, A. M., Thoning, K. W., Hall, B. D., Elkins, J. W., and Steele, L. P.: Conversion of NOAA atmospheric dry air $\mathrm{CH}_{4}$ mole fractions to a gravimetrically prepared standard scale, J. Geophys. Res.-Atmos., 110, D18306, doi:10.1029/2005JD006035, 2005.

Enting, I. G., Trudinger, C. M., and Francey, R. J.: A synthesis inversion of the concentration and delta $13 \mathrm{C}$ of atmospheric $\mathrm{CO}_{2}$, Tellus B, 47, 35-52, doi:10.1034/j.1600-0889.47.issue1.5.x, 1995.

Fan, S.: A Large Terrestrial Carbon Sink in North America Implied by Atmospheric and Oceanic Carbon Dioxide Data and Models, Science, 282, 442-446, doi:10.1126/science.282.5388.442, 1998.

Galewsky, J., Rella, C., Sharp, Z., Samuels, K., and Ward, D.: Surface measurements of upper tropospheric water vapour isotopic composition on the Chajnantor Plateau, Chile, Geophys. Res. Lett., 38, 1-5, doi:10.1029/2011GL048557, 2011.

Gupta, P., Noone, D., Galewsky, J., Sweeney, C., and Vaughn, B. H.: Demonstration of high-precision continuous measurements of water vapour isotopologues in laboratory and remote field deployments using wavelength-scanned cavity ring-down spectroscopy (WS-CRDS) technology, Rapid communications in mass spectrometry?, Rapid Commun. Mass. Spectrom., 23, 2534-2542, 2009.

Gurney, K. R., Law, R. M., Denning, A. S., Rayner, P. J., Baker, D., Bousquet, P., Bruhwiler, L., Chen, Y.-H., Ciais, P., Fan, S., Fung, I. Y., Gloor, M., Heimann, M., Higuchi, K., Jasmin, J., Maki, T., Maksyutov, S., Masarie, K., Peylin, P., Prather, M., Pak, B., Randerson, J., Sarmiento, J., Taguchi, S., Takahaski, T., and Yuen, C.-W.: Towards robust regional estimates of $\mathrm{CO}_{2}$ sources and sinks using atmospheric transport models, Nature, 415, 626630, doi:10.1038/415626a, 2002.

IPCC: Summary for Policymakers, in: Climate Change 2007: The Physical Science Basis. Contribution of Working Group I to the Fourth Assessment Report of the Intergovernmental Panel on Climate Change, edited by: Solomon, S., Qin, D., Manning, M., Chen, Z., Marquis, M., Averyt, K. B., Tignor, M., and Miller, H. L., Cambridge University Press, Cambridge, United Kingdom and New York, NY, USA, 2007.

Keeling, C. D.: The Concentration and Isotopic Abundances of Carbon Dioxide in the Atmosphere, Tellus, 12, 200-203. doi:10.1111/j.2153-3490.1960.tb01300.x, 1960.

Keeling, R. F.: Measuring correlations between atmospheric oxygen and carbon dioxide mole fractions: A preliminary study in urban air, J. Atmos. Chem., 7, 153-176,1988.

Keeling, R. F. and Shertz, S. R.: Seasonal and interannual variations in atmospheric oxygen and implications for the global carbon cycle, Nature, 358, 723-727, 1992.

Lauvaux, T., Gioli, B., Sarrat, C., Rayner, P. J., Ciais, P., Chevallier, F., Noilhan, J., Miglietta, F., Brunet, Y., Ceschia, E., Dolman, H., Elbers, J. A., Gerbig, C., Hutjes, R., Jarosz, N., Legain, D., and Uliasz, M.: Bridging the gap between atmospheric concentrations and local ecosystem measurements, Geophys. Res. Lett., 36, L19809, doi:10.1029/2009GL039574, 2009.

Lauvaux, T., Schuh, A. E., Uliasz, M., Richardson, S., Miles, N., Andrews, A. E., Sweeney, C., Diaz, L. I., Martins, D., Shepson, P. B., and Davis, K. J.: Constraining the $\mathrm{CO}_{2}$ budget of the corn belt: exploring uncertainties from the assumptions in a mesoscale inverse system, Atmos. Chem. Phys., 12, 337-354, doi:10.5194/acp-12-337-2012, 2012a.

Lauvaux, T., Schuh, A. E., Bocquet, M., Wu, L., Richardson, S., Miles, N., and Davis, K. J.: Network design for mesoscale inversions of $\mathrm{CO}_{2}$ sources and sinks, Tellus B, 64, 17980, doi:10.3402/tellusb.v64i0.17980, 2012b.

$\mathrm{Ma}$, S. and Skou, E.: $\mathrm{CO}_{2}$ permeability in Nafion ${ }^{\circledR}$ EW1100 at elevated temperature, Solid State Ionics, 178, 615-619, doi:10.1016/j.ssi.2007.01.030, 2007.

Matross, D. M., Andrews, A., Pathmathevan, M., Gerbig, C., Lin, J. C., Wofsy, S. C., Daube, B. C., Gottlieb, E. W., Chow, V. Y., Lee, J. T., Zhao, C., Bakwin, P. S., Munger, J. W., and Hollinger, D. Y.: Estimating regional carbon exchange in New England and Quebec by combining atmospheric, ground-based and satellite data, Tellus B, 58, 344-358, doi:10.1111/J.1600-0889.2006.00206.X, 2006.

McKain, K., Wofsy, S. C., Nehrkorn, T., Eluszkiewicz, J., Ehleringer, J. R., and Stephens, B. B.: Assessment of groundbased atmospheric observations for verification of greenhouse gas emissions from an urban region, Proc. Natl. Acad. Sci. USA, 109, 8423-8428, doi:10.1073/pnas.1116645109, 2012.

Nara, H., Tanimoto, H., Tohjima, Y., Mukai, H., Nojiri, Y., Katsumata, K., and Rella, C. W.: Effect of air composition $\left(\mathrm{N}_{2}, \mathrm{O}_{2}\right.$, Ar, and $\left.\mathrm{H}_{2} \mathrm{O}\right)$ on $\mathrm{CO}_{2}$ and $\mathrm{CH}_{4}$ measurement by wavelength-scanned cavity ring-down spectroscopy: calibration and measurement strategy, Atmos. Meas. Tech., 5, 2689-2701, doi:10.5194/amt-5-2689-2012, 2012.

Peters, W., Jacobson, A. R., Sweeney, C., Andrews, A. E., Conway, T. J., Masarie, K., Miller, J. B., Bruhwiler, L. M. P., Pétron, G., Hirsch, A. I., Worthy, D. E. J., van der Werf, G. R., Randerson, J. T., Wennberg, P. O., Krol, M. C., and Tans, P. P: An atmospheric perspective on North American carbon dioxide exchange: CarbonTracker, Proc. Natl. Acad. Sci. USA, 104, 18925-18930, doi:10.1073/pnas.0708986104, 2007.

Peters, W., Krol, M. C., van der Werf, G. R., Houweling, S., Jones, C. D., Hughes, J., Schaefer, K., Masarie, K. A., Jacobson, A. R., Miller, J. B., Cho, C. H., Ramonet, M., Schmidt, M., Ciattaglia, L., Apadula, F., Heltai, D., Meinhardt, F., di Sarra, A. G., Piacentino, S., Sferlazzo, D., Aalto, T., Hatakka, J., Ström, J., Haszpra, L., Meijer, H. A. J., van der Laan, S., Neubert, R. E. M., Jordan, A., Rodo, X., Morgui, J.-A., Vermeulen, A. T., Popa, E., Rozanski, K., Zimnoch, M., Manning, A. C., Uglietti, C., Dolman, A. J., Ciais, P., Heiman, M., and Tans, P. P.: Seven years of recent European net terrestrial carbon dioxide exchange constrained by atmospheric observations, Global Change Biol., 16 1317-1337, doi:10.1111/j.1365-2486.2009.02078.x, 2010.

Peylin, P., Bousquet, P., Le Quéré, C., Sitch, S., Friedlingstein, P., McKinley, G., Gruber, N., Rayner, P., and Ciais, P.: Multiple constraints on regional $\mathrm{CO}_{2}$ flux variations over land and oceans, Global Biogeochem. Cy., 19, GB1011, doi:10.1029/2003GB002214, 2005.

Richardson, S., J., Miles, N. L., Davis, K. J., Crosson, E. R., Rella, C. W., and Andrews, A. E.: Field Testing of Cavity Ring-Down Spectroscopy Analyzers Measuring Carbon Dioxide and Water Vapor, J. Atmos. Ocean. Technol., 29, 397-406, doi:10.1175/JTECH-D-11-00063.1, 2012.

Schuh, A. E., Denning, A. S., Corbin, K. D., Baker, I. T., Uliasz, M., Parazoo, N., Andrews, A. E., and Worthy, D. E. J.: A 
regional high-resolution carbon flux inversion of North America for 2004, Biogeosciences, 7, 1625-1644, doi:10.5194/bg-71625-2010, 2010.

Shlens, J.: A Tutorial on Principle Component Analysis, available at: http://www.snl.salk.edu/ $\sim$ shlens/pca.pdf (last access: 24 January 2013), 2009.

Tolk, L. F., Peters, W., Meesters, A. G. C. A., Groenendijk, M., Vermeulen, A. T., Steeneveld, G. J., and Dolman, A. J.: Modelling regional scale surface fluxes, meteorology and $\mathrm{CO}_{2}$ mixing ratios for the Cabauw tower in the Netherlands, Biogeosciences, 6 , 2265-2280, doi:10.5194/bg-6-2265-2009, 2009.

WMO: Report of the 15th WMO/IAEA Meeting of Experts on Carbon Dioxide, Other Green-house Gases, and Related Tracers Measurement Techniques, 7-10 September 2009, GAW Report No. 194, WMO TD No. 1553, available at: http://www.wmo.int/pages/prog/arep/gaw/documents/ GAW194WMOTDNo1553, 2011a.

WMO: WMO Greenhouse Gas Bulletin, ISSN 2078-0796, available at: http://www.wmo.int/pages/prog/arep/gaw/ghg/ documents/GHGbulletin_7_en.pdf, 2011b.
Varghese, P. L. and Hanson, R. K.: Collisional narrowing effects on spectral line shapes measured at high resolution, Appl. Opt., 23, 2376-2385, doi:10.1364/AO.23.002376, 1984.

Welp, L. R., Keeling, R. F., Weiss, R. F., Paplawsky, W., and Heckman, S.: Design and performance of a Nafion dryer for continuous operation at $\mathrm{CO}_{2}$ and $\mathrm{CH}_{4}$ air monitoring sites, Atmos. Meas. Tech. Discuss., 5, 5449-5468, doi:10.5194/amtd-5-54492012, 2012.

Winderlich, J., Chen, H., Gerbig, C., Seifert, T., Kolle, O., Lavrič, J. V., Kaiser, C., Höfer, A., and Heimann, M.: Continuous lowmaintenance $\mathrm{CO}_{2} / \mathrm{CH}_{4} / \mathrm{H}_{2} \mathrm{O}$ measurements at the Zotino Tall Tower Observatory (ZOTTO) in Central Siberia, Atmos. Meas. Tech., 3, 1113-1128, doi:10.5194/amt-3-1113-2010, 2010.

Zellweger, C., Steinbacher, M., and Buchmann, B.: Evaluation of new laser spectrometer techniques for in-situ carbon monoxide measurements, Atmos. Meas. Tech., 5, 2555-2567, doi:10.5194/amt-5-2555-2012, 2012.

Zhao, C. L. and Tans, P. P.: Estimating uncertainty of the WMO mole fraction scale for carbon dioxide in air, J. Geophys. Res., 111, D08S09, doi:10.1029/2005JD006003, 2006. 